\title{
The coarticulation-duration relationship in early Quechua speech
}

\author{
Margaret Cychosz ${ }^{\mathrm{a}}$ \\ ${ }^{a}$ Center for Comparative and Evolutionary Biology of Hearing and Department of Hearing and Speech Sciences, University \\ of Maryland-College Park, 0100 Samuel J. LeFrak Hall, College Park, USA, mcychosz@umd.edu
}




\begin{abstract}
Evidence from acoustic and articulatory phonetics suggests that children coarticulate more than adults, but previous work has focused on the instantiation of coarticulation with phonology in a typologically homogeneous sample. The interplay of coarticulation with children's speaking rate has also been ignored. How do coarticulation and speaking rate (duration) interact over the course of development, and does the interaction manifest differently across distinct morphological environments? To answer this, the current study measured the speech patterns of bilingual QuechuaSpanish children (5-10 years) and adults. Coarticulation and duration were measured in two word environments, within morphemes and across morpheme boundaries. Unsurprisingly, adults consistently coarticulated more in shorter duration sequences, in both morphological environments. The children's coarticulation-duration patterns, however, varied by morphological environment. Additionally, the children's speech patterns, but not the adults', were sensitive to prosodic length: children produced increasingly shorter phones in words with more syllables. It is suggested that the differences between adults and children are attributable to adults' faster speaking rate and increased dominance in Quechua.
\end{abstract}

Keywords: coarticulation; speaking rate; acoustics; field phonetics; first language acquisition; morphology; Quechua 


\section{Introduction}

Much research into child speech development suggests that children coarticulate more than adults, with the degree and variability of coarticulation decreasing as children age (Goodell and Studdert-Kennedy 1992, Nittrouer, Studdert-Kennedy, and McGowan 1989, Nittrouer, Studdert-Kennedy, and Neely 1996, Noiray, Wieling, Abakarova, Rubertus, and Tiede 2019 Zharkova, Hewlett, Hardcastle, and Lickley|2014 Zharkova, Hardcastle, and Gibbon|2018).

Citing this evidence, some have argued that child coarticulation reflects children's larger, syllable-sized phonological representations, which gradually individuate into phoneme-sized units over the course of development.

However, previous research on child coarticulation has been limited in several key ways. First, these results did not take into account children's speaking rate, which is crucial both because children speak slower than adults Smith 1992) and also because coarticulation is positively correlated with speaking rate, at least in adult speech \begin{tabular}{|l|l|l|l|l|l|}
\hline Agwuele, Sussman, and Lindblom 2008, Gay 1981, Matthies, Perrier, Perkell, and Zandipour 2001). Second, with
\end{tabular} one exception, previous work only studied the interaction of children's coarticulation with phonology, and not other levels of language, such as morphology (cf. Song, Demuth, Shattuck-Hufnagel, and Ménard 2013). But, just as previous work on child coarticulation allowed us to infer about the potentially larger size of children's phonological representations, studying coarticulation patterns by morphological environment could eventually lend insight into the status of children's early word forms. Finally, previous results on child coarticulation were drawn from typologicallyhomogeneous linguistic samples. Not extending the study of coarticulation to more diverse language samples limits the conclusions that can be drawn about the developmental timecourse of speech phenomena, like coarticulation and speaking rate, that are assumed to follow a universal developmental path. Increased linguistic diversity may unearth distinct developmental trajectories that interact with the language(s) being learned and the sociolinguistic context.

To that end, this study tracks the development of coarticulation and duration, across and within morpheme boundaries, in adults and a cross-sectional cohort of Quechua-speaking children. Here, the coarticulation-duration relationship is quantified as the slope between the degree of coarticulation within VC sequences and VC sequence duration. In doing so, this work integrates and expands upon two distinct lines of research: the development of coarticulation in child speech (e.g., Nittrouer et al. 1989, Noiray, Wieling, et al. 2019 Song, Demuth, ShattuckHufnagel, and Ménard 2013; Zharkova et al. 2018) and the relationship between linguistic structure and speech production (e.g., Hay 2003; Plag 2014; Song, Demuth, Evans, and Shattuck-Hufnagel 2013 Strycharczuk 2019 Tomaschek, Tucker, Ramscar, and Baayen under review). 


\section{Background}

\subsection{Child coarticulation: Evidence from phonology}

The degree and variability of children's coarticulation appears to decrease with age (Goodell and StuddertKennedy 1992, Nittrouer et al. 1989; Nittrouer et al. 1996. Noiray, Wieling, et al. 2019; Zharkova et al. 2014. Zharkova et al. 2018 inter alia). While one could expect children to coarticulate less than adults - children speak slower and with less coordinated movement (Smith 1992) results from these studies suggest that unlike adult coarticulation, child coarticulation does not necessarily reflect efficiency in speech planning or the clear anticipation of upcoming segments (Bradlow 2002; Whalen 1990). Instead, many authors have interpreted this relationship between coarticulation and age as evidence that young children represent speech in syllable-sized units, which gradually individuate into phonemes over the course of development (see Cychosz, Munson, and Edwards [2021] and Noiray, Popescu, et al. [2019] for theoretical overview).

Nittrouer et al. (1989) measured coarticulation in fricative-vowel sequences to test the anticipatory effect of vowels on $/ \mathrm{s} /$ and $/ \mathrm{J} /$. Their results from children 3;0-8;0 showed that children coarticulated more than adults, leading the authors to conclude that the children had more holistic, syllable-sized representations (see also Nittrouer et al. 1996). More recently, the coarticulation patterns of children with and without apraxia of speech and adults without apraxia were studied. The typically-developing children once again showed more intra- and inter-syllabic anticipatory coarticulation than the adults, while the children with apraxia of speech showed high amounts of variability and idiosyncratic coarticulation patterns (Nijland et al. 2002$)$.

Zharkova and colleagues (Zharkova, Hewlett, and Hardcastle 2011, Zharkova et al. 2014, Zharkova et al. 2018) and Noiray and colleagues (Noiray, Abakarova, Rubertus, Krüger, and Tiede 2018; Noiray, Wieling, et al. 2019. Rubertus and Noiray 2018) have also frequently observed that children coarticulate more than adults. In Zharkova et al. (2011), children aged (6;3-9;9) altered their productions of $/ \mathrm{d} /$ based on the following vowel $(/ \mathrm{a}, \mathrm{i}$, or $\mathrm{u} /)$ more than adults, although Zharkova et al. (2014) conducted a similar experiment and did not find any differences between children (aged 10;0-12;4) and adult coarticulation patterns, suggesting that children may approximate adultlike phonological representations by preadolescence. Noiray, Wieling, et al. (2019) measured vocalic anticipation in children (3;05-7;06) and adults and found that in V\#CV strings, children anticipated the upcoming vowel sooner than adults at age $3 ; 0$ and 5;0, but progressively less by 7;0. Finally, Noiray, Popescu, et al. (2019) correlated children's (aged 4;06-7;02) coarticulation with measures of expressive vocabulary and phonological awareness (a measure of speaker awareness of segmental units), and demonstrated that gestural individuation was negatively correlated with phonological awareness, which suggested that coarticulation decreased over the course of development.

Results in the child coarticulation literature can be somewhat mixed, with some work concluding that adults coarticulate more than children. Children would then learn to coordinate and exhibit appropriate coarticulatory 
overlap as part of standard phonetic and/or phonological development (Barbier et al. 2013 ; Barbier et al. 2015. Katz, Kripke, and Tallal 1991, Kent 1983 Whiteside and Hodgson 2000). Other works have found no differences in coarticulatory patterns between adults and children (Flege 1988 Goffman, Smith, Heisler, and Ho 2008 , Noiray, Ménard, and Iskarous 2013, Sereno and Lieberman 1987, Sereno, Baum, Marean, and Lieberman 1987).

These differences notwithstanding, most of the child coarticulation literature suggests that children coarticulate more than adults. But our understanding of coarticulatory development is still incomplete in several key ways. For one thing, in adult speech, it has long been known that coarticulation is positively correlated with speaking rate

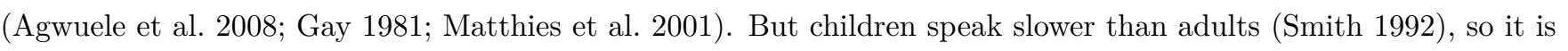
possible that the robust adult pattern of increased coarticulation in faster speech may not manifest in children.

Our understanding of coarticulation in child speech is also limited by the units of analysis. In adult speech, coarticulation - and duration - are known to vary by morphological environment (see Plag (2014) and Strycharczuk (2019) for recent overviews). For example, Cho (2001) found that intergestural timing in Korean was more stable within a word than across a morpheme boundary and for a lexicalized compound word versus a non-lexicalized compound word (noun phrase). (See also Strycharczuk and Scobbie [2016] and Lee-Kim, Davidson, and Hwang [2013]). It is possible that morphological structure manifests in children's coarticulation patterns as well, but only one study to date has examined this: Song, Demuth, Shattuck-Hufnagel, and Ménard (2013) employed acoustic and ultrasound analyses to study adult and two-year-old English-speaking children's CC syllable (/ks/) coarticulation in the coda of bimorphemic (rocks) and monomorphemic (box). Children reliably raised their tongue more for rocks than box, suggesting that they could distinguish between word environments. While there was no evidence of anticipatory coarticulation for box in the adults or children studied, there was a strong preservatory coarticulation effect of $/ \mathrm{k} /$ on $/ \mathrm{s} /$ in box and anticipatory coarticulation effect of $/ \mathrm{s} /$ on $/ \mathrm{k} /$ in rocks, indicating that the articulatory target differed by morphological role. With the exception of this study, there is a complete lack of understanding how coarticulation interacts with word structure in child speech. This absence is even more problematic when one considers how the study of child coarticulation interacting with phonology has provided significant insight to the status of children's phonological representations, as described in this literature overview. Studying the intersection of coarticulation, duration, and morphological environment could thus be a very preliminary step to understanding the status of children's early word forms.

\section{Current study}

\subsection{The language}

This study measures children's coarticulation-duration patterns in South Bolivian Quechua, henceforth Quechua, a Quechua-II/C language with over 1.6 million speakers in southwest Bolivia and northwest Argentina (Torero 1964). This variety of Quechua is spoken in the Chuquisaca department of southern Bolivia. Like many Quechuan varieties, 
Quechua in southern Bolivia has been in intense contact with Spanish for hundreds of years resulting in large amounts of language mixing and borrowing (Muysken 2012a Muysken 2012b). Furthermore, public schools in Bolivia are conducted primarily in Spanish. Consequently, almost all school-age children who speak Quechua in the home, such as the children in the present study, are bilingual in Spanish. And because of Spanish schooling, children in Bolivia learn to read in Spanish. Though Quechua has an established writing system, children generally do not learn to read or write in Quechua and few Quechua speakers use the language in its written form.

Quechua is a highly-agglutinating language with over 200 productive nominal and verbal suffixes that encode argument structure and grammatical relations (for comparison, English has around 35 productive suffixes). The morphology is nevertheless highly regular and not subject to significant morphophonological processes or fusion. The phonological inventory includes three phonemic vowels $/ \mathrm{i}, \mathrm{a}, \mathrm{u} /$ and two allophonic vowels derived in uvular contexts [e, o] (Gallagher 2016). The consonantal inventory contrasts voiceless stops, aspirated stops, and ejectives along four places of articulation, /p, t, k, q/, as well as a three-way alveopalatal stop-aspirated stop-ejective distinction $/ \mathrm{t}$, $\mathrm{f}^{\mathrm{h}}$, t'/. Nasals are contrasted along three places of articulation, /m, n, n/ with an allophonic velar nasal. See Appendix A for a complete consonant inventory.

As an agglutinating language, Quechua provides unique insight into interactions of coarticulation, duration, and morphological structure. Quechua speakers appear to have highly flexible inflectional and derivational lexicons: suffixes and roots are abstracted away from the original lexical contexts and are easily rearranged for novel stem+suffix pairings. This process is similar to how speakers of more analytic languages, such as English, effortlessly arrange novel noun-adjective pairings. Given the number of possible complex word forms, it is difficult to doubt the morphological productivity of young Quechua speakers. Quechua is understudied, both in child language research and linguistics more broadly. Still, much like well-studied, less synthetic languages, there is undeniable evidence of morphological productivity in children's speech (and other highly agglutinating languages). Child speakers of Cuzco Quechua appear to have a productive morphology by age 5;0, if not earlier (Courtney \& Saville-Troike 2002). Cuzco Quechua and South Bolivia Quechua are distinct varieties, but they are mutually-intelligible. There should be no reason to assume that children's morphological productivity would vary greatly between them.

Another reason why Quechua may be an interesting addition to the literature concerns its applied use in Bolivia. Few Quechua speakers read or write in the language (speakers who attend school instead become literate in Spanish). Disengaging prosodic effects from orthographic effects has been immensely difficult in phonetic speech science (Seyfarth, Garellek, Gillingham, Ackerman, and Malouf 2018, Warner, Good, Jongman, and Sereno 2006). Quechua removes this problematic variable because speakers do not have strong orthographic representations. There is a standardized, written form of South Bolivian Quechua. For example, students who study Quechua at the university level learn to read and write in the language and some textbooks for school-aged children contain some words written in Quechua. Furthermore, Quechua speakers certainly can write in Quechua, because the orthogra- 
phy is relatively transparent and Quechua shares many phonological characteristics with Spanish (e.g., five vowel system). Nevertheless, orthographic effects should be minimal, making Quechua a unique language to examine the coarticulation-duration relationship over development, and how it manifests in different morphological environments.

\subsection{Research objectives}

The primary objective of this paper is to measure the development of the coarticulation-duration relationship in a large, cross-sectional cohort of Quechua-speaking children. To accomplish this, a relatively novel acoustic measure of coarticulation is employed, which has been validated for young children's voices and a variety of consonants (Cychosz, Edwards, Munson, \& Johnson 2019). The choice to study coarticulation-duration was made because speakers tend to coarticulate more in fast speech (Agwuele et al. 2008, Gay 1981; Matthies et al. 2001), and adults speak faster than children. These factors make it especially important to measure, and control for, speaking rate when measuring differences in coarticulation between different age groups. This question is tested in a tightly-controlled experimental paradigm where coarticulation between, and the duration of, the phones $[\mathrm{a}]$ and $[\mathrm{p}]$ or $[\mathrm{a}]$ and $[\mathrm{m}]$ are measured.

1. Do child Quechua speakers coarticulate more than adult Quechua speakers and how does this change through development in this cross-sectional sample?

1a. How does children's coarticulation interact with duration (speaking rate) throughout development?

This work predicts that children will overall coarticulate more than adults (Nittrouer et al. 1989 , Noiray, Wieling, et al. 2019; Smith 1992 Zharkova et al. 2018) and that, like adults, they will coarticulate more in faster speech. However, it is possible that the coarticulation-duration relationship will not be as robust in children, or could even be reversed, given that children coarticulate for different reasons than adults.

There is evidence that both coarticulation and duration reflect linguistic structure in child speech (e.g., Song, Demuth, Evans, and Shattuck-Hufnagel 2013 Song, Demuth, Shattuck-Hufnagel, and Ménard 2013), so a secondary objective of this paper is to study the coarticulation-duration relationship by word environment in the adults' and children's speech.

2. How does the coarticulation-duration relationship manifest within morphemes (e.g., papa 'potato') versus across morpheme boundaries (e.g., papa-pi 'potato-LOC') in adult and child Quechua speech? How does this change over development?

Given the developing literature documenting effects of word structure upon speech production in children and adults (e.g., Song, Demuth, Shattuck-Hufnagel, and Ménard 2013), this study predicts that children's coarticulationduration patterns will differ by word environment. However, manifestation of the coarticulation-duration pattern in the children's speech will differ from the adults' pattern: children may be less likely than adults to reliably 
differentiate between morphological environments. This prediction does not suggest that Quechua-speaking children are morphologically unproductive. Instead, the prediction reflects recent proposals in child speech and language research that children may initially analyze language differently than adults and, as a result, children may, for a time early in development, store language more holistically than adults do (Davis and Redford 2019, Redford 2019). The prediction that children's speech patterns by morphological environment will differ from adults' also does not claim that speakers do not develop abstract language or that speakers store every experienced multisyllabic/multiword sequence in perpetuity. Instead, coarticulation-duration differences across word environments by age could indicate that linguistic representations are probabilistic and exist at multiple levels in the grammar. If we ignore biases like literacy and linguistic concepts like words and phonemes, it actually makes sense that young children, who are not exposed to written language and have limited experience with spoken language, might have different coarticulationduration patterns by morphological environment. This work empirically tests this theory.

\section{Methods}

\subsection{Participants}

Fifty-one children, aged 5;0-10;11, and ten female adults (adult $\mu_{\text {age }}=23, \sigma=5.46$, three did not report age) participated in this study. Children's age was as follows: 10 five-year-olds $(\mu=5 ; 7, \sigma=0 ; 4 ; 6$ girls, 4 boys, one did not report), 10 six-year-olds ( $\mu=6 ; 5, \sigma=0 ; 2 ; 5$ girls, 8 boys), 13 seven-year-olds $(\mu=7 ; 7, \sigma=0 ; 4 ; 3$ girls, 8 boys), 8 eight-year-olds ( $\mu=8 ; 8, \sigma=0 ; 2 ; 4$ girls, 5 boys, one did not report), 5 nine-year-olds $(\mu=9 ; 4, \sigma=0 ; 3 ; 2$ girls, 3 boys, two did not report), and 5 ten-year-olds ( $\mu=10 ; 8, \sigma=0 ; 4 ; 1$ girl, 4 boys, two did not report). The recording for one of the adult participants contained significant wind interference and was removed from analysis leaving $\mathrm{n}=9$ adults. All participants were bilingual Spanish-Quechua speakers living in or around a mid-size town in southern Bolivia. The children were either recruited at a local primary school where the author was volunteering $(\mathrm{n}=13)$, or through personal contacts in the surrounding communities $(n=38)$. The adult participants were recruited through local contacts. This research was approved by the UC Berkeley Institutional Review Board.

Most children had typical speech and hearing development, per parental and/or teacher self-report. The caregivers of $n=3$ children ( 2 seven-year-olds, 1 five-year-old) stated that their child was late to begin talking. Late talker status was not collected from the participants recruited from the school. These communities are medically under-served so some language delays and/or impairments may go unreported. Additionally, n=3 children had lost one or more of their top or bottom front teeth at the time of recording. (The presence of front teeth could have notable consequences for speech acoustics [e.g., anterior fricatives].) An attempt to conduct a hearing screening for the children was made. However, it became clear after attempting with a few of the children during pilot testing that false positives were being collected during the test as some children were nervous and/or afraid of making a mistake. Consequently, it cannot be said with absolute confidence that all children would have passed a standard 
hearing screening. The adult participants did not report any speech or language disorders.

To gauge socioeconomic status (SES), information on the central caregiver's education level (usually the mother, occasionally the grandmother) was collected from those families recruited from the surrounding community, but not those recruited at the school. There is no a priori reason to believe that the distribution of socioeconomic strata of the children recruited at the school would differ from those who were recruited from elsewhere in the community - the children from the surrounding communities likewise attended school, just in a different location from where the school children were recruited and tested. SES, usually implemented as mother's level of education in child development research, is an important predictor of child language development in the United States (Hoff 2003; Pace, Luo, HirshPasek, and Golinkoff 2017). However, it is not clear if SES is predictive of language outcomes in all cultural or linguistic contexts. Specifically, it is unknown if SES predicts language development in Bolivia as a whole, in these speech communities specifically, or for children learning Quechua. Still, SES information is reported here as it is an important predictor in many other cultural contexts. There were 7 sibling pairs (no twins), and 1 three-sibling pair, in the child sample resulting in 43 unique caregivers. For the 31 community-recruited caregivers, education levels were: $\mathrm{n}=17$ caregivers $(59 \%)$ completed some primary school (less than six years of education), $\mathrm{n}=5(17 \%)$ completed primary school (6 years of education), $\mathrm{n}=3$ (10\%) completed the equivalent of a middle school (10 years of education), $\mathrm{n}=3$ (10\%) completed secondary/high school (13 years of education) and $\mathrm{n}=2$ (7\%) had not received any formal schooling. Two caregivers did not report.

An additional indicator of SES in these communities in Bolivia may be the central caregiver's familiarity with Spanish, which indicates that the caregiver had the opportunity to attend school (conducted in Spanish) for a longer period of time. A coarse estimation of the central caregiver's level of Quechua-Spanish bilingualism was also collected from those families recruited from the surrounding community: $\mathrm{n}=6$ (21\% of caregivers from the community) were monolingual Quechua speakers, n=5 (17\%) were Quechua-dominant but spoke/understood some Spanish, n=17 (59\%) were bilingual Quechua-Spanish speakers, and $\mathrm{n}=1$ did not report.

\subsection{Tasks}

The child participants completed four picture-prompted real word and nonword repetition tasks. The tasks were given in the following order: 1) real word repetition, including a morphological extension component (to be explained in the following sections), 2) Quechua nonword repetition, 3) Spanish nonword repetition, and 4) additional real word repetition with morphological extension. For all tasks, children repeated the real words or nonwords after a pre-recorded model speaker. The nonword repetition data are not analyzed in this paper and are not further discussed.

The adult participants only completed the two real word repetition tasks because even the eldest children 
approached ceiling on the nonword repetition tasks. Because much of the children's data was collected during the school day, the entire testing procedure had to be relatively short and executable in one sitting. The experimental procedure took approximately 30-40 minutes per child and 20 minutes per adult. For their participation, all children could choose an item from a toy bag. Children at the school additionally received academic assistance and lessons on English and Spanish from the author who was volunteering at the school. Additional donations such as school supplies and books were made to the school. The adult participants and caregivers of children from the surrounding communities who did not attend the school instead received a small monetary sum.

\subsection{Stimuli}

The real word repetition tasks consisted of 56 high-frequency Quechua nouns (plus 6 training trials for 62 total lexical items) that are familiar to children learning Spanish and Quechua in southern Bolivia (stimuli listed in Appendix B). Neither Bolivian Spanish nor any Quechuan language has an equivalent to the Macarthur Bates Communicative Development Inventory (Fenson et al. 2007), which reports stages of age-normed vocabulary development. Nor do these languages have any large, transcribed child-directed speech corpus from which to infer vocabulary development. For these reasons, children's knowledge of the test items was confirmed via a pre-test that demonstrated that children as young as 3;0 recognized all items. Female caregivers also confirmed that children as young as 3;0 should recognize the items.

To derive an across morpheme environment in Quechua, nouns are inflected with suffixes (e.g., llama 'llama' > llama-pi 'llama-LOC'). As a result almost all of the across morpheme stimuli in this study are at least one syllable longer in length than the within morpheme stimuli. For example, within morpheme stimuli are frequently two syllable base roots (e.g., llapa 'lightning' and llama 'llama'). However, across morpheme stimuli are often three syllable inflections of these nouns (e.g., llapa-pi 'lightning-LOC' and llama-pi 'llama-LOC'). Even for prosodically-longer within morpheme stimuli such as the three syllable stimulus hampiri 'healer' or four syllable stimulus hatunmama 'grandmother', there are equivalent across morpheme stimuli that are one syllable longer (e.g., hatunmama-man 'grandmother'). To control for the prosodic differences between conditions, and ensure that any acoustic differences by word environment were attributable to morphological structure and not word length, a parameter Syllable Count was included in all statistical modeling. By controlling for stimulus length, we can be more confident in any observed effects of word environment upon speech production.

In addition to selecting high-frequency lexical items, likely to be recognized by the children and easily represented in a photo, these particular lexical stimuli were also chosen because they contained the sequence [ap] or [am] within a morpheme (e.g., papa 'potato') or crossing a morpheme boundary (e.g., thapa-pi 'prairie-LOC'). (Quechua is predominantly open-syllabic, so all VC syllables transcend syllable boundaries.) To control for acoustic correlates 
of stress, the phone [a] in the biphone sequence additionally had to fall in the syllable carrying primary stress. The only exception to this was the item ham'piri 'healer', and its inflected form hampi'ri-pi 'healer-LOC', where the [am] sequence does not coincide with primary stress. These items were included because it was difficult to find sufficient items for the within morpheme condition that adhered to the criterion of frequency, recognition by children, etc. Thus, of the original 56 real word test items, this study measured coarticulation on a subset that contained the biphone sequence [ap] $(\mathrm{n}=23)$ or $[\mathrm{am}](\mathrm{n}=23)$ (see Appendix $\mathrm{C}$ for list of stimuli that elicited [ap] and Appendix $\mathrm{D}$ for the stimuli that elicited $[\mathrm{am}])$. Note that some lexical items contained both within and across stimuli (e.g., [am] and [ap] in llama-pi 'llama-LOC'). The experimental hypotheses remain the same for both the [ap] and [am] biphone sequences. However, given the acoustic measure of coarticulation employed here -spectral distance - overall there is less "coarticulation" between the phones in [ap] than the phones in [am] due to the increased acoustic similarity of the phones in $[\mathrm{am}]$ (voiced, sonorous).

Much previous work on child coarticulation has studied fricative-vowel sequences (e.g., Zharkova et al. 2011). This was not possible in the current study as there are no fricative-initial nominal case markers in Quechua. The VC sequences [ap] and [am] were instead chosen to examine coarticulatory effects for several reasons. First, instead of CV sequences, VC sequences were chosen because all Quechua nominal case-marking suffixes are consonant-initial (e.g., '- $q$ ' Genitive, '-manta' ABlative). Consequently, it is not possible to elicit a CV sequence that crosses a noun-case marker boundary in Quechua. Then, of the possible VC sequences, [ap] and [am] were chosen because coarticulatory measures are highly dependent upon segmentation decisions. The acoustic delimitation between vowels and voiceless stops/vowels and nasals is relatively obvious and not subjective.

The two suffixes - $p i$ and - man (pronounced [may]) were also chosen for several specific reasons. First, nominal case markers were chosen because nouns are easier to represent in picture prompts than derived word forms (e.g., puñu-y 'to sleep' > puñu-chi-y 'to make (one) sleep') or verb conjugations. Second, nouns are grammatical in Quechua with just one suffix. Some conjugated verbs require multiple suffixes (see previous 'sleep' example), which would make elicitation and tight control of the experimental stimuli more difficult. By using nominal suffixes, elicitation could be isolated to a single stem+suffix combination. Finally, the locative and allative markers were used because, absent a large corpus of child-directed Quechua speech, it is reasonable to assume that the locative - $p i$ and allative -man on high-frequency nouns, such as those elicited, will be relatively frequent in a child's input.

Given all of these considerations - the need for high-frequency, child-friendly words, the correct prosodic environment, frequent suffixes, and segments that were easily segmented - it was challenging to identify lexical items for use in the experiment. Still, with $(n=35)$ unique items in the across morpheme boundary condition and $(n=11)$ unique items in the within boundary condition, this study uses more distinct lexical items than most previous studies of morphological effects on speech production in children or adults (Lee-Kim et al. 2013, Song, Demuth, Shattuck-Hufnagel, and Ménard 2013). 
The real word stimuli came from recordings of an adult female bilingual Quechua-Spanish speaker. These recordings were digitized at a sampling frequency of $44.1 \mathrm{kHz}$ using a portable Zoom H1 Handy Recorder. Stimuli were normed for amplitude between words, but not duration, since some words had ejectives, fricatives, etc. that are temporally longer. The real word picture stimuli were color photographs of the objects. These picture stimuli are available for viewing and reuse in the Open Science Framework project repository affiliated with this work (Cychosz 2020b).

Children in these communities have limited exposure to technology (some mothers have flip phones but most children are unfamiliar with computing devices). Consequently, instead of presenting each picture stimulus on a screen, which could have been culturally inappropriate, pictures were presented on individual pages clipped into an $11 \times 12.4$ " plastic binder. For this reason, the words were not entirely randomized for each participant. Instead, two different randomized lists were created with approximately half of the children and adults completing the first list and half completing the second. Since there were more across morpheme stimuli than within morpheme stimuli (it was much more difficult to find stimuli for the within morpheme condition), participants repeated the within morpheme stimuli three times in the experiment and the across morpheme stimuli two times. Repetitions of the same stimulus were always separated by at least two different stimuli and were presented with a novel photo of the item each time.

\subsection{Data collection}

For the experimental phase, participants were seated on the ground or on a stool, side-by-side with the experimenter. Audio stimuli were played for the experimenter and participant from an iTunes playlist run on an iPhone 6. Each participant wore AKG K240 binaural studio headphones and the experimenter wore Apple earpods to follow along with the experiment; both headphones were connected to the iPhone with a Belkin headphone splitter.

For data collection, the participant first heard the audio stimulus (a bare noun) and was simultaneously presented with the accompanying photo in the binder. The participant was instructed to simply repeat the bare noun after the model speaker. The participant was then instructed to produce the word again in inflected form. For the inflected form, the two morphemes described in section 4.3 were elicited. The locative marker -pi was elicited in the first real word repetition task and the allative marker - man was elicited in the second task. Ideally, all of the participants' productions would have been spontaneous instead of repeated. However, in a previous version of a similar word elicitation task, with different children, it was found that the youngest children frequently became too nervous and hesitant to follow the task when not prompted with the word. Elicited imitation paired with a visual stimulus is also the method used in the previous study on coarticulatory effects within and between morpheme boundaries (Song, Demuth, Shattuck-Hufnagel, \& Ménard 2013). 
For the children, the inflected forms were elicited using a large plastic toy insect. For the locative marker -pi, the toy insect was placed on top of the picture stimulus and the child was prompted, "Where is the bug?" In response, the child produced the word with the correct suffixal carrier, e.g., llama-pi (kasan) (llama-LOC COP-3Ps, "(It is) on the llama."). For the allative marker - man, the researcher wiggled and moved the toy insect on the page towards the noun in question and prompted the child, "Where is the bug going to?," to which the child would produce the word with the suffixal carrier, e.g., llama-man (risan) (llama-ALL go-3PS, "(It is going) to/towards the llama."). Children often caught on to the elicitation technique and anticipated the upcoming inflected noun; consequently, although the researcher conducting the experiment tried to encourage children to wait for the prompted question, it was not possible to have all child productions be in response to a question. The adult participants were merely told to add the relevant morpheme to each prompted word in a carrier phrase. For the first real word task, the carrier phrase was, "I say in the two times" (Noqa nini -pi iskay kutita). For the second task, the phrase was, "I say to/towards the two times" (Noqa nini -man iskay kutita). The experimenter would then manually advance to the next stimulus item.

In a pilot version of this study, the researcher attempted to get young children to produce the target words in a carrier phrase so that the elicitation technique would be uniform between adults and children. However, children under seven years could not reliably inflect and repeat the words in a carrier phrase. As a result, the different data elicitation techniques between adults and children introduce a confound for a study testing developmental differences in speech patterning. The children were responding to a wh-question, and therefore emphasized the target noun, while the adults merely embedded the target noun in a carrier phrase.

Eliciting participant responses in quasi-sentential contexts such as these may disguise the contrasts between inflected and base word forms since "phonetic variation between orthographically-distinct homophones increases when the target homophones are dictated in isolated word list or in contrastive sentences" (Seyfarth et al., 2018:35). The elicitation methods used here thus discourage metalinguistic awareness to the degree possible given the number of lexical items needed for the experiment.

Participant responses were recorded with a portable Zoom H1 Handy Recorder at a $44.1 \mathrm{kHz}$ sampling rate. Children were rewarded with stickers throughout the task and many additionally chose to help the experimenter flip through the pages of the binder.

\subsection{Data analysis}

Each participant's audio file was first hand-aligned to the word level in Praat (Boersma \& Weenink 2020). A Quechua forced aligner was trained on all of the participants' data using the Montreal Forced Aligner (McAuliffe, Socolof, Mihuc, Wagner, \& Sonderegger 2017) to align the words to the phone level. (The trained Quechua aligner 
used in the study is available at https://github.com/megseekosh/kid_align). The phone-level alignment was subsequently hand-checked by one of two trained phoneticians. One of these phoneticians was blind to the hypothesis of the current experiment. Alignment was conducted auditorily and by reviewing the associated acoustic waveform and broadband spectrogram in Praat.

Acoustic measures, coarticulation in particular, can be sensitive to alignment decisions, so a number of parameters were set prior to alignment to ensure segmentation reliability. Word-initial plosive, affricate, and ejective onset corresponded to the burst. Vowel onset (e.g., for the [ap] sequences) corresponded to the onset of periodicity (in the event of a preceding voiceless consonant) and/or stable formant structure (in the event of a preceding voiced consonant) in the waveform and spectrogram. Nasals were differentiated (e.g., for the [am] sequences) by the presence of anti-formants in the spectrogram and a reduction in intensity in the waveform. Additional parameters were set (e.g., for rhotics) but are irrelevant for the segments under analysis in the current study.

To evaluate agreement between the phoneticians conducting the alignment, both phoneticians aligned two randomly-selected word lists, one from a child aged 5;9 and another from a child aged 7;4. For the 5;9 child's list, the difference between the aligners' average consonant duration was $4 \mathrm{~ms}$ and the average difference in vowel duration was $2 \mathrm{~ms}$. Pearson correlations between the aligners for the 5;9 child's list were significant for consonants: $\mathrm{r}=0.86$ $\mathrm{p}<.001,95 \% \mathrm{CI}=[0.83,0.89]$ and vowels: $\mathrm{r}=0.94 \mathrm{p}<.001,95 \% \mathrm{CI}=[0.93,0.96]$. For the $7 ; 4$ child's list, the difference between the aligners' average consonant duration was $2 \mathrm{~ms}$ and the average difference in vowel duration was $2 \mathrm{~ms}$. Pearson correlations between the aligners for the 7;4 child's list were significant for consonants: $\mathrm{r}=0.98 \mathrm{p}<.001,95 \%$ $\mathrm{CI}=[0.97,0.98]$ and vowels: $\mathrm{r}=0.95 \mathrm{p}<.001,95 \% \mathrm{CI}=[0.94,0.96]$. The high levels of agreement between aligners suggest high fidelity to the alignment protocol.

Much of the work that uses acoustic instead of articulatory coarticulation techniques employs measures such as center of gravity for fricatives, Peak equivalent rectangular bandwidth (ERB ${ }_{\mathrm{N}}$ ) Reidy, Kristensen, Winn, Litovsky, \& Edwards 2017), or formant-based measurements (e.g., transitions or spectral peaks) for vowels (Lehiste and Shockey 1972, Öhman 1966). However, valid estimates of child formants and even sonorants are notoriously difficult to measure (Chen, Whalen, \& Shadle 2019). In this study, coarticulation is instead measured as the spectral distance between two phones, a technique that has been validated for children's speech and a variety of consonants (Cychosz et al. 2019; Gerosa, Lee, Giuliani, and Narayanan 2006). For this analysis, Mel-frequency log spectra were measured over the middle third of two adjacent phones (e.g., [a] and [p]). For stops, the average spectra was computed over the burst. From these spectral vectors, an average spectrum was computed for each phone. Finally, the Euclidean distance between the averaged spectra was computed where a greater Euclidean distance equated to less coarticulation between the phones and a smaller Euclidean distance equated to more coarticulation. Using this technique, both coarticulation between $\mathrm{VC}$ sequences and the $\mathrm{VC}$ sequence duration were measured automatically using a custom Python script running Librosa functions (McFee et al. 2015), now available open- 
source (https://github.com/megseekosh/Meas_Quechua_coartic).

\section{Results}

The primary research objective of this study is to measure the coarticulation-duration relationship by morphological environment in adult and child Quechua speech. Results begin with descriptive statistics concerning the amount of coarticulation and VC sequence duration by age group and morphological environment (within versus between morphemes). Then, a series of models are fit to predict coarticulation and duration by age and morphological environment. These models are complemented by an analysis highlighting how coarticulation interacts with duration differently in adults and children, and how this varies in the two morphological environments. Scripts to compile these results and fit the models are publicly available (https://github.com/megseekosh/Meas_Quechua_coartic).

All analyses were conducted in the RStudio computing environment (version: 1.3.1056; RStudio Team 2020). Data visualizations were created with ggplot2 (Wickham 2016). Modeling was conducted using the lme4 (Bates, Maechler, Bolker, \& Walker 2015), ImerTest (Kuznetsova, Brockhoff, \& Christensen 2017), and glmmTMB (Brooks et al. 2017) packages and summaries were presented with papaja (Aust \& Barth 2018) and Stargazer (Hlavac 2018). Tests of residual normality were conducted using the normtest package (Gavrilov \& Pusev 2014). The significance of potential model parameters was determined using a combination of log-likelihood comparisons between models, AIC estimations, and p-values procured from model summaries. In all models, continuous predictors were mean-centered to facilitate model interpretation.

\subsection{Modeling interaction of coarticulation and duration}

Coarticulation. The degree of coarticulation between the VC sequences [ap] and [am] was measured using the spectral distance metric described in the Methods. For this metric, coarticulation is quantified as the Euclidean distance between the spectral vectors of two adjacent phones, henceforth the Mel spectral distance. A larger spectral distance between phones equates to less coarticulation between the phones.

Table 1 shows the mean Mel spectral distance between the segments in [ap] (words inflected with -pi for the across morpheme boundary condition) and Table 2 shows this for [am] (words inflected with -man for the across morpheme boundary condition). Unsurprisingly, there is a larger average spectral distance between the vowel and plosive in [ap] than the vowel and nasal in [am] because the segments in [am] have increased acoustic similarity (sonority, voicing). Next, looking by age group for coarticulation between [ap] shows, contrary to the first hypothesis, that the amount of coarticulation between segments increases as children age. This is likely due to the increased speaking rate in the older cohorts and adults, as will become apparent when these results are crossed with sequence duration. This result reinforces the importance of considering speaking rate when evaluating developmental differences in coarticulation. There is also a large amount of between-child variability, even within age group (see 
Appendices I for by-speaker plots). For example, the eight-year-old children appear to have the largest spectral distance between $[\mathrm{a}]$ and $[\mathrm{p}]$, but the group SD is also highest.

There is less within-group variability in [ap] productions in the adult speakers (reflected in the adults' smaller SD of the mean). Furthermore, variability does not appear to decrease linearly as both the nine and ten-year-old cohorts exhibit larger SDs than the five and six-year-olds. However, this could also reflect the smaller sample sizes in the older cohorts (5 ten-year-olds and 5 nine-year-olds but 10 each in the five- and six-year-old cohorts).

For the coarticulation patterns between segments in [am], adults and children coarticulate similarly, irrespective of age group. Again, this is surprising given previous work showing that children coarticulate differently than adults. There is slightly greater variability in the amount of coarticulation (larger SD) in the adult group.

Table 1

Mean spectral distance between [a] and [p] by age and word position

\begin{tabular}{lrrrrr}
\hline & \multicolumn{2}{c}{ Across boundary } & & \multicolumn{3}{c}{ Within boundary } \\
\cline { 2 - 3 } \cline { 5 - 6 } Age & Spectral Distance & SD & & Spectral Distance & SD \\
\hline 5 & 17.42 & 4.64 & & 19.63 & 4.56 \\
6 & 17.62 & 4.70 & & 19.78 & 4.59 \\
7 & 17.04 & 4.68 & & 19.18 & 5.90 \\
8 & 18.50 & 6.03 & & 21.35 & 6.76 \\
9 & 16.21 & 7.02 & & 17.51 & 7.79 \\
10 & 14.92 & 5.09 & & 15.93 & 5.07 \\
adult & 14.99 & 3.64 & & 14.51 & 3.03 \\
\hline
\end{tabular}

Table 2

Mean spectral distance between [a] and [m] by age and word position

\begin{tabular}{lrrrrr}
\hline & \multicolumn{3}{c}{ Across boundary } & & \multicolumn{3}{c}{ Within boundary } \\
\cline { 2 - 3 } \cline { 5 - 6 } Age & Spectral Distance & SD & & Spectral Distance & SD \\
\hline 5 & 7.94 & 3.13 & & 8.71 & 3.39 \\
6 & 8.44 & 3.08 & & 9.54 & 4.76 \\
7 & 8.43 & 3.11 & & 8.86 & 3.80 \\
8 & 9.89 & 3.99 & & 9.73 & 3.78 \\
9 & 7.43 & 2.64 & & 8.06 & 3.11 \\
10 & 8.21 & 3.43 & & 8.30 & 4.25 \\
adult & 7.44 & 4.19 & & 7.00 & 3.34 \\
\hline
\end{tabular}

Duration. The following descriptive statistics outline the interaction of coarticulation and sequence duration. Duration interacts with coarticulation, and age, as speakers coarticulate more in fast speech (Gay, 1981), and adults speak faster than children (Lee, Potamianos, \& Narayanan 1999).

Table 3 maps average sequence duration of [ap] by age and word position and Table 4 does so for [am]. Duration of [ap] decreases with age, with adult speakers exhibiting the shortest average [ap] duration for both word positions. 
The average duration of [ap] sequences within morphemes tended to be longer than the duration of [ap] sequences across boundaries for all of the children. This pattern was reversed in the adult speakers whose average [ap] duration within morpheme boundaries was actually shorter than across. The patterns by morphological environment will be revisited in the following section of the Results.

Table 3

Mean duration of [ap] sequence by age and word position

\begin{tabular}{lrrrrr}
\hline & \multicolumn{2}{c}{ Across boundary } & & \multicolumn{2}{c}{ Within boundary } \\
\cline { 2 - 3 } \cline { 5 - 6 } Age & Duration $(\mathrm{ms})$ & SD & & Duration $(\mathrm{ms})$ & SD \\
\hline 5 & 228.7 & 47 & & 339.9 & 52 \\
6 & 242.5 & 45 & & 334.4 & 59 \\
7 & 245.1 & 57 & & 319.8 & 60 \\
8 & 226.9 & 56 & & 329.3 & 43 \\
9 & 216.6 & 36 & & 312.6 & 56 \\
10 & 212.8 & 50 & & 302.3 & 63 \\
adult & 205.7 & 47 & & 197.0 & 59 \\
\hline
\end{tabular}

Turning to the sequence [am], the average duration of [am] in adult speakers was shorter than all of the children; and like $[\mathrm{ap}],[\mathrm{am}]$ duration also decreases with age, across and within morphemes. Overall, these results reaffirm the finding that children speak faster as they age.

Table 4

Mean duration of [am] sequence by age and word position

\begin{tabular}{lrrrrr}
\hline & \multicolumn{2}{c}{ Across boundary } & & \multicolumn{2}{c}{ Within boundary } \\
\cline { 2 - 3 } \cline { 5 - 6 } Age & Duration (ms) & SD & & Duration (ms) & SD \\
\hline 5 & 214.4 & 45 & & 251.2 & 66 \\
6 & 217.9 & 58 & & 247.8 & 62 \\
7 & 209.8 & 42 & & 244.6 & 60 \\
8 & 218.2 & 63 & & 247.1 & 53 \\
9 & 199.8 & 30 & & 231.8 & 64 \\
10 & 194.3 & 33 & & 239.9 & 57 \\
adult & 175.6 & 36 & & 173.7 & 39 \\
\hline
\end{tabular}

Concerning differences by word position, all child age groups showed, on average, shorter [am] durations in the across morpheme condition, contrary to the finding that [ap] sequence duration was longer in the across morpheme condition for adults. However, the average duration of [am] by word position in adults only differed by approximately $2 \mathrm{~ms}$ while the average within morpheme condition in children was approximately $30 \mathrm{~ms}$ greater than the across morpheme condition. Thus, for both [am] and [ap] sequences, there appears to be a difference in sequence duration by word position for adult and child speakers. In the following section we turn to the modeling of coarticulation before illustrating how degree of coarticulation interacts with duration differently in the adults and children. 
Modeling. A series of generalized linear mixed effect models (GLMMs) were fit to predict degree of coarticulation (Mel spectral distance between each V and C). GLMMs were chosen instead of the more common linear mixed effect models due to the non-normality of the residual VC Sequence duration (henceforth simply Sequence Duration) which was included in all models. Specifically, the response variable Spectral distance and the residual Sequence duration are both limited to non-negative values (as all VC sequences had some distance between the $\mathrm{V}$ and $\mathrm{C}$ and all had a duration), with a resultant right skew to the data distribution. Shapiro tests of kurtosis and skewness for Sequence duration indicated that we could reject the null hypothesis that the residual's distribution did not differ significantly from a normal distribution. Kurtosis $\mathrm{t}=5.53, \mathrm{p}<.001$ and skewness: $\mathrm{t}=1.07, \mathrm{p}<.001$ (Shapiro, Wilk, \& Chen 1968).

The choice to fit gamma GLMMs, as opposed to log-normalizing Sequence duration and fitting linear mixed models, reflects some recent suggestions in cognitive psychology to avoid data transformation, even for commonlytransformed variables such as time, duration, or response time, to facilitate between-study comparison (Liceralde 2018 Lo and Andrews 2015). However, there is not yet a consensus in the literature on the use of transformed versus untransformed variables. Consequently, gamma GLMMs were fit using a log linking function to appropriately model the skewed, non-Gaussian distribution of the residual. Then, in a supplementary analysis, all modeling procedures were replicated with linear mixed effects models that included a transformed Sequence duration variable. Final model results were broadly consistent across the two modeling approaches; see Supplementary analysis for details.

Baseline GLMMs included random slopes of Participant by Word. Model building then began in a forwardtesting manner with predictors added in the following order: Syllable Count (fit with weighted effect coding for all models), Sequence duration, VC sequence ([ap] or [am]), Age (adult or child), Environment ([within morpheme or between morphemes]), and interactions. Syllable Count was included in the modeling in an attempt to isolate the effect of Environment on speech production from prosodic structure since within-morpheme stimulus items tended to be shorter than across-morpheme items (see Methods). ${ }^{1}$

The best model fit included Syllable Count and the four-variable interaction of Sequence duration, VC sequence, Age, and Environment. This four-variable interaction indicates that the relationship between coarticulation and duration differs between adults and children. Given the difficulty in interpreting four-variable interactions, separate models were fit for adults and children to facilitate coefficient interpretation. The summary for the model containing adults and children together is included in Appendix E.

Best model fit for the adult and child models included Syllable Count and the three-variable interaction of Sequence duration, VC sequence, and Environment: the improvement of models with this interaction over models with the four independent effects was significant for the adult model at alpha level $<.05\left(\chi^{2}=11.18, \mathrm{df}=9,13\right.$ $\mathrm{p}=.02)$ and the child model $\left(\chi^{2}=36.52, \mathrm{df}=9,13, \mathrm{p}<.001\right)$. The final adult model summary is listed in Table 5 and the child model summary is listed in Table 6 In the model summaries, the coefficients and standard error 
measurements were multiplied by 100 to make the otherwise small coefficients more interpretable. This step does not affect the direction or magnitude of the effect between predictors and outcome variables.

For the child model, the addition of the variable Age Group (levels: 5, 6, 7, 8, 9, 10; fit with weighted effect coding) improved upon a model with Syllable Count and the interaction of Sequence duration, VC sequence, and Environment. The direction of the effect of Age Group indicates that the child participants tended to coarticulate more with age, just as the adults studied coarticulated more than the children, likely because the older children and adults spoke faster.

In the adult and child models, a positive coefficient for the predictor VC sequence, with the reference level '[am]', shows that there was greater spectral distance between the segments in [ap] than [am], as we would anticipate given the acoustic signatures of $[\mathrm{m}]$ (voiced, sonorant) versus [p] (voiceless, transient) (adult model: $\beta=60.66, \mathrm{z}=9.59$, $\mathrm{p}<.001$; child model: $\beta=71.3, \mathrm{z}=21.39, \mathrm{p}<.001)$.

A positive coefficient for Sequence duration indicates that longer duration VC sequences tend to be less coarticulated (greater spectral distance between phones) (child model: $\beta=0.09, \mathrm{z}=4.15, \mathrm{p}<.001$; adult model: $\beta=0.36$, $\mathrm{z}=6.45, \mathrm{p}<.001)$. The coefficients suggest that when speakers, both adults and children alike, speak slower, they tend to coarticulate less. There is, however, an interaction between several of these predictors, which will demonstrate that children in particular do not always coarticulate less in longer-duration sequences. The direction of the interaction between Sequence duration, VC sequence, and Environment differs between the adult and child speakers so this will be interpreted separately for the two groups in the following section.

Finally, the parameter Syllable Count was significant for the adult and child models, though the effect differed by group. Children tended to coarticulate progressively more in longer words. Adults coarticulated differently by word size, but coarticulation did not increase in longer words. These unanticipated age differences will be explored in the following section of the results.

Adults. For the adult model, the interaction between Sequence duration, VC sequence, and Environment suggests a difference in the relationship between the response variable - amount of coarticulation - and Sequence duration that differs by Environment and VC sequence. As Figure 1 demonstrates, this difference by Environment is apparent in the steepness of the slope for the 'across morpheme' and 'within morpheme' conditions for [am] and [ap]. To quantify this difference for the sequence [am], the slopes of the two conditions were calculated. To reflect the data visualizations, these slopes were calculated on the beta coefficients before the coefficients were scaled by 100. As the [am] panel in Figure 1 1 suggests, the slope for the 'within morpheme' condition was steeper (2.14) than the slope for the 'across morpheme' condition (2.06), suggesting a different relationship between duration and coarticulation between the two word environments in adults.

Overall, the significance of the interaction Sequence duration, VC sequence, and Environment in adult speakers shows two important results: first, adults distinguish by word environment, both for [ap] versus [a\#p] 


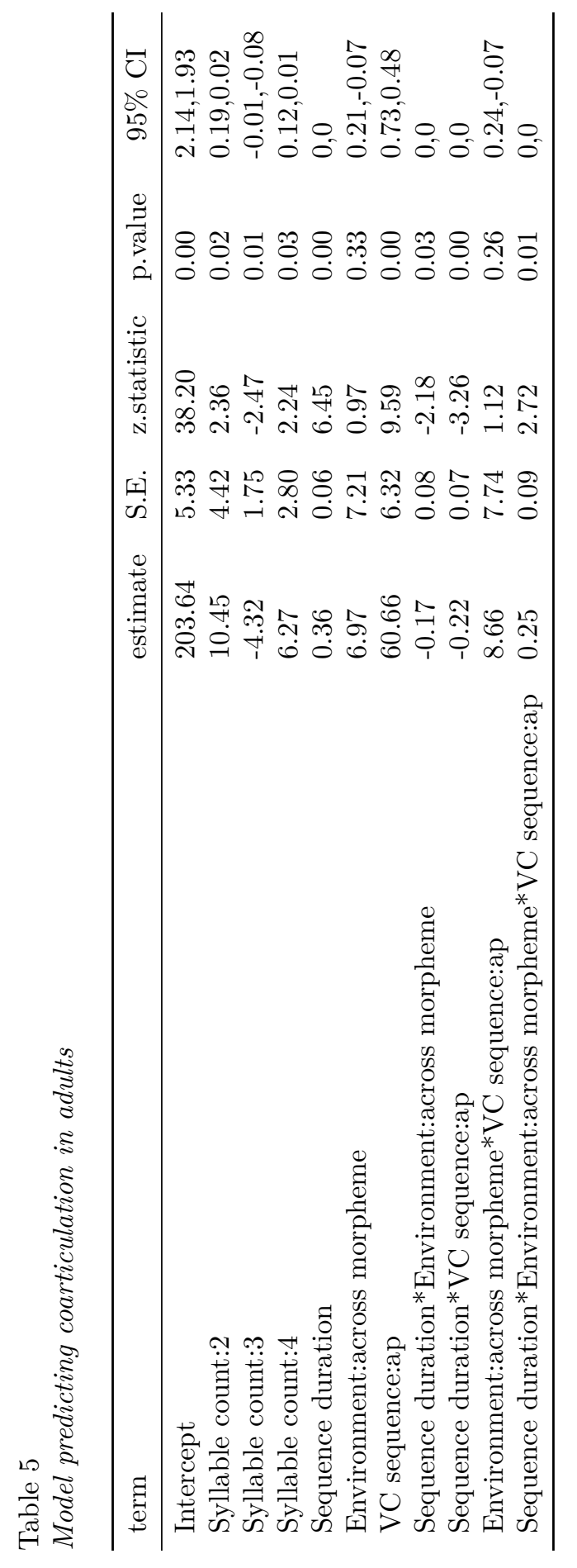




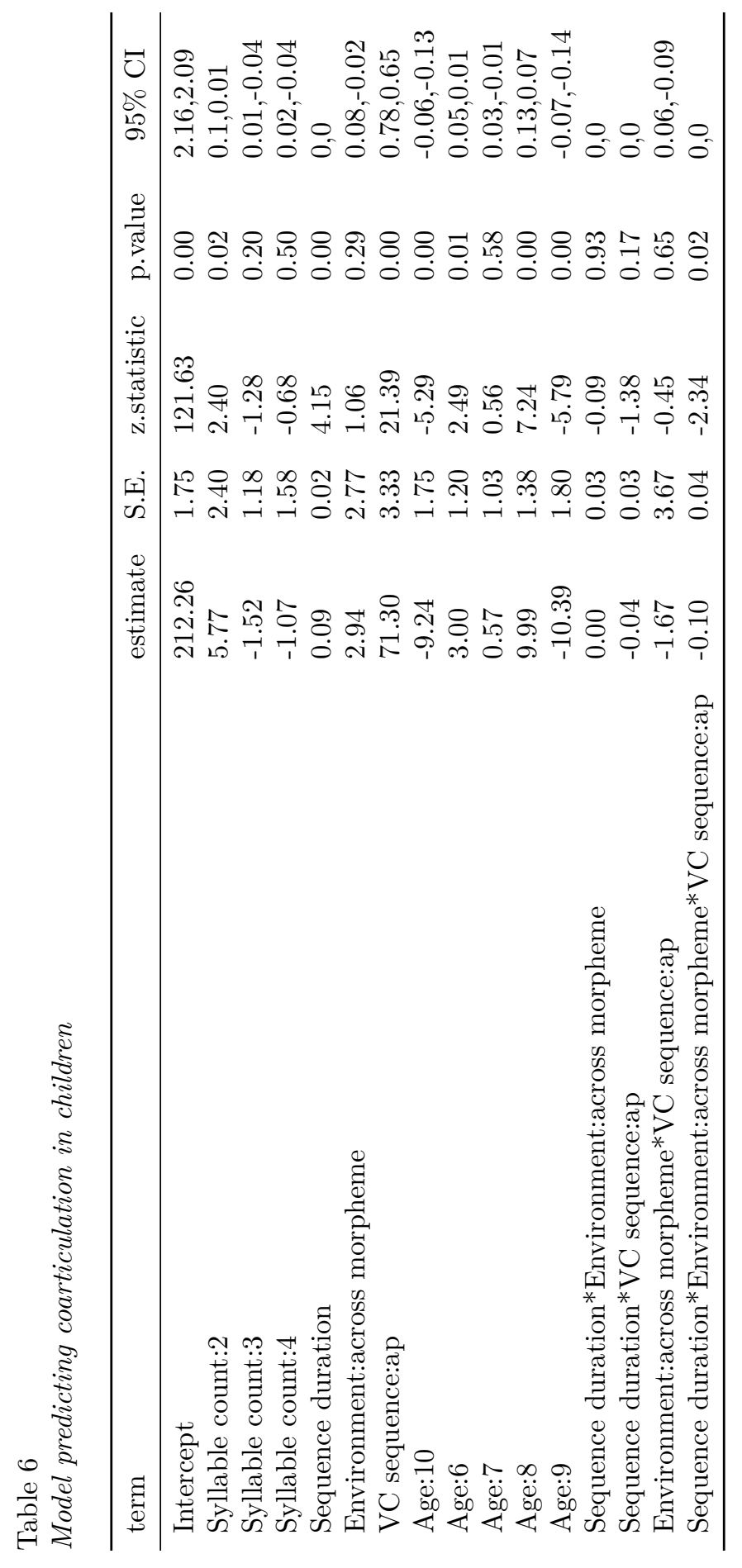


sequences and $[\mathrm{am}]$ versus $[\mathrm{a} \# \mathrm{~m}]$ sequences. Second, complicating this finding, is the fact that adults distinguish between word environments differently depending upon the VC sequence. For [ap], though adults coarticulate roughly equally across and within morphemes, the relationship between duration and coarticulation (longer duration equates to less coarticulation) is stronger in the 'across morpheme' condition. For [am], adults also distinguish between the two morphological environments by the relationship of $\mathrm{VC}$ duration and coarticulatory degree, but the effect of condition is reversed: the relationship between duration and coarticulation is stronger for the 'within morpheme' condition.

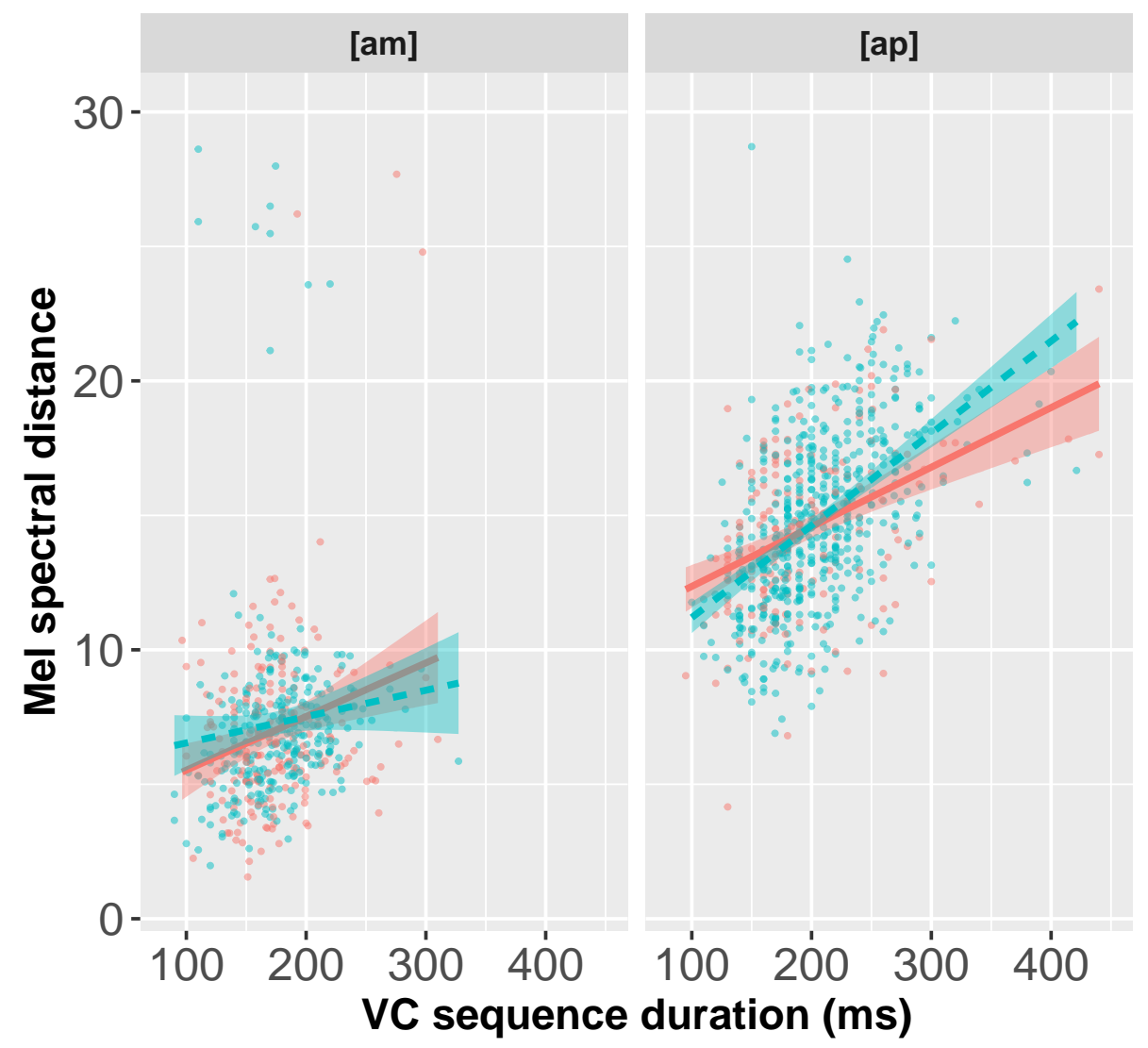

\section{Environment}

within morpheme

across morpheme

Figure 1. Coarticulation within VC sequence by sequence duration and morphological environment in adult speakers

Thus, returning to one of the central research questions - does adult coarticulation-duration differ by word environment - we find that adults do coarticulate differently in the two word environments. Despite the differences by word environment, there was still a positive relationship between duration and amount of coarticulation for all combinations of VC sequences and word environments. Adults consistently coarticulate less in longer-duration sequences. This result suggests that adult speakers may have one overarching articulatory plan for all environments and both VC sequences measured. The following section demonstrates how this relationship between duration and coarticulation may not be uniform between adults and children. 
Children. In the child model, the significant interaction of Sequence duration, VC sequence, and Environment suggests that children do not coarticulate similarly in longer-duration sequences for all combinations of Environment and VC sequence (Figure22). Specifically, for [ap] sequences that occur across morpheme boundaries, the negative slope indicates that children actually coarticulate more in longer duration sequences. The positive slope for the within morpheme boundary condition suggests that children coarticulate less in longer-duration sequences, in line with all of the adult patterns. So, children coarticulate more between segments at morpheme boundaries in words inflected with the locative marker - $p i$ than between those same segments that occur within morphemes.

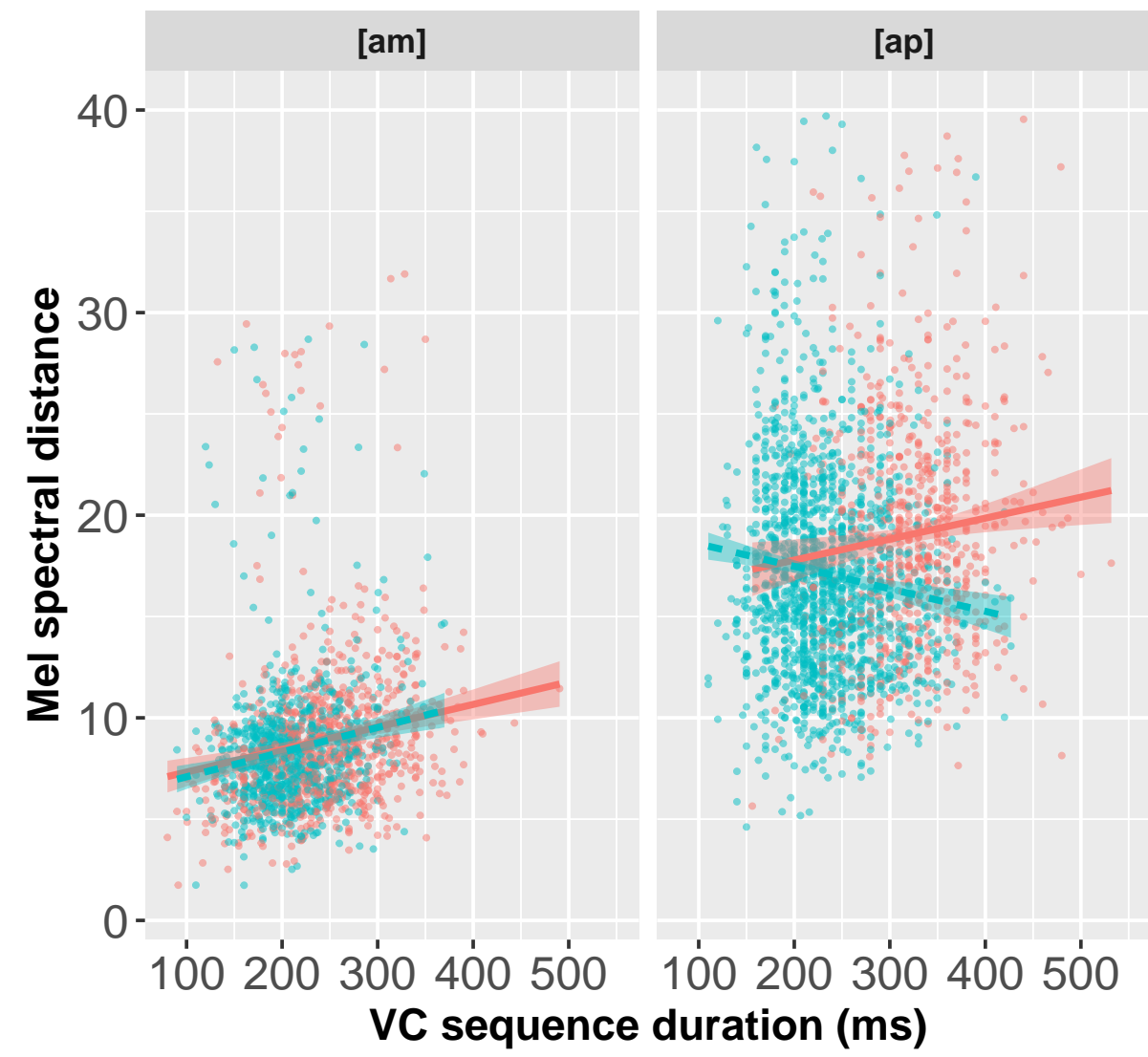

\section{Environment}

within morpheme

across morpheme

Figure 2. Coarticulation within VC sequence by sequence duration and morphological environment in all child speakers

This negative relationship between duration and spectral distance is counter to the positive relationship for every combination of $\mathrm{VC}$ sequence and word environment in adult speakers. Adults consistently coarticulate less in longer-duration sequences regardless of environment or $\mathrm{VC}$ sequence. The facet plot in Figure 3 plots this relationship between duration and coarticulation for [ap] for each age group (5-10 years) to ensure a consistent pattern. All age groups show the same negative relationship: the longer the [ap] sequence, the more the children coarticulate between $[\mathrm{a}]$ and $[\mathrm{p}]$ in the across morpheme condition. 


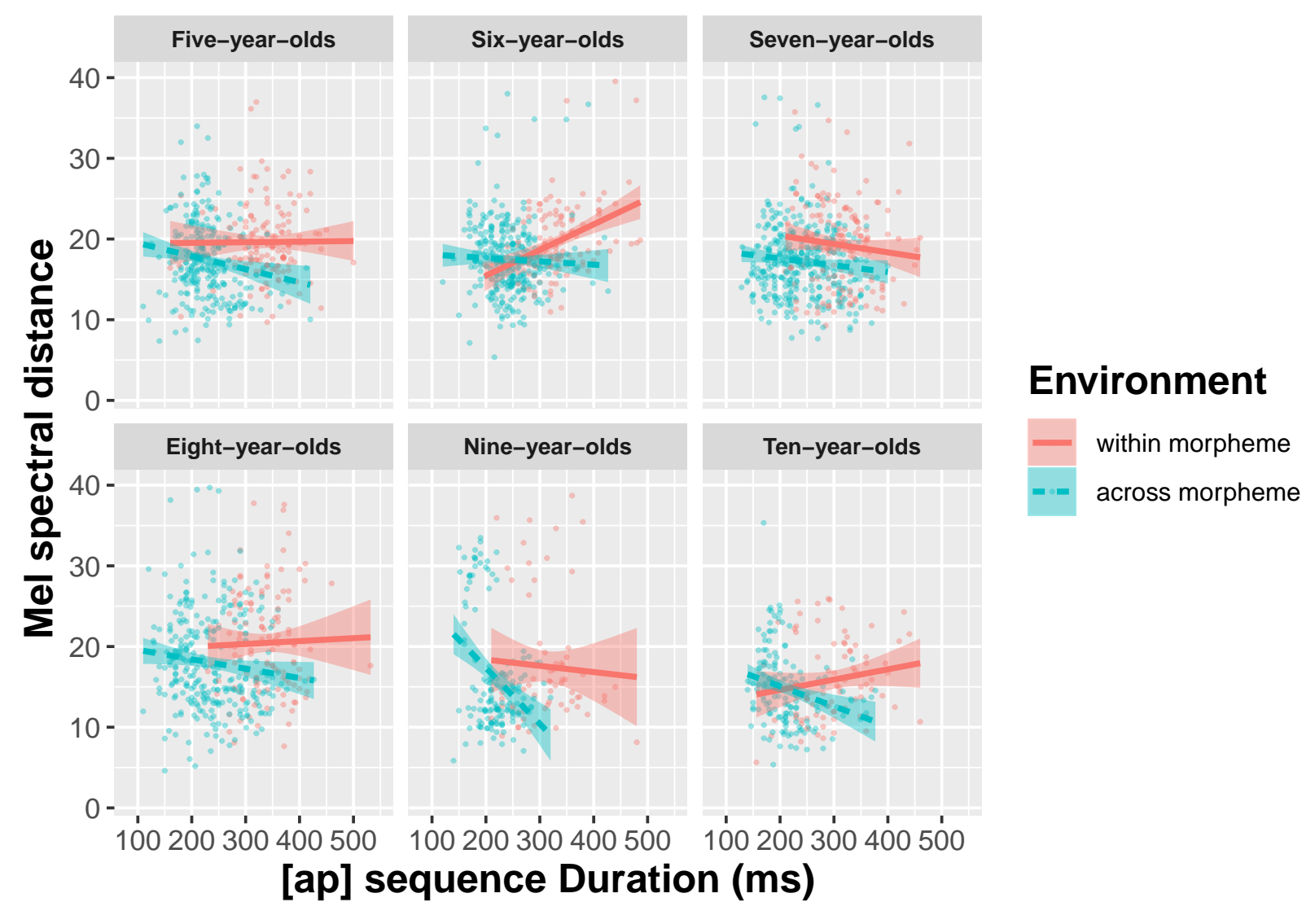

Figure 3. Coarticulation within [ap] by sequence duration, morphological environment, and age in child speakers

The results for $[\mathrm{am}]$ in children demonstrate broadly similar results to the adult speakers: children coarticulate less between segments in longer-duration [am] sequences. The facet plot in Figure 4 once again shows a similar effect for each age group. Given the between-subject variability that typically characterizes child speech, these patterns by environment are further broken apart by individual child for each age group (age 5-10) (Appendix I) to ensure no large outliers with regards to the patterning by word environment. The results are broadly similar across speakers.

In sum, modeling results suggest that, contrary to previous results, children do not necessarily coarticulate more than adults. This result is attributable to adults' and older children's faster speaking rates. Furthermore, modeling results showed that adults have one, overarching plan for both morphological environments, and even both VC sequences: they consistently coarticulated more in faster speech, although the different slopes by environment suggest that adults still distinguish by environment in their speech. For the most part, children's duration-coarticulation relationship mirrors the adults'. The stark difference between adults and children emerges in the [ap] sequence. Children differentiate between morphological environments via the relationship between duration and coarticulation as they coarticulate more in longer-duration sequences across morpheme boundaries and coarticulate less in longerduration sequences within morphemes. For words inflected with -man, children show a similar pattern to adults, though children do not differentiate by environment coarticulatorily. Rather, across morpheme sequences are shorter 


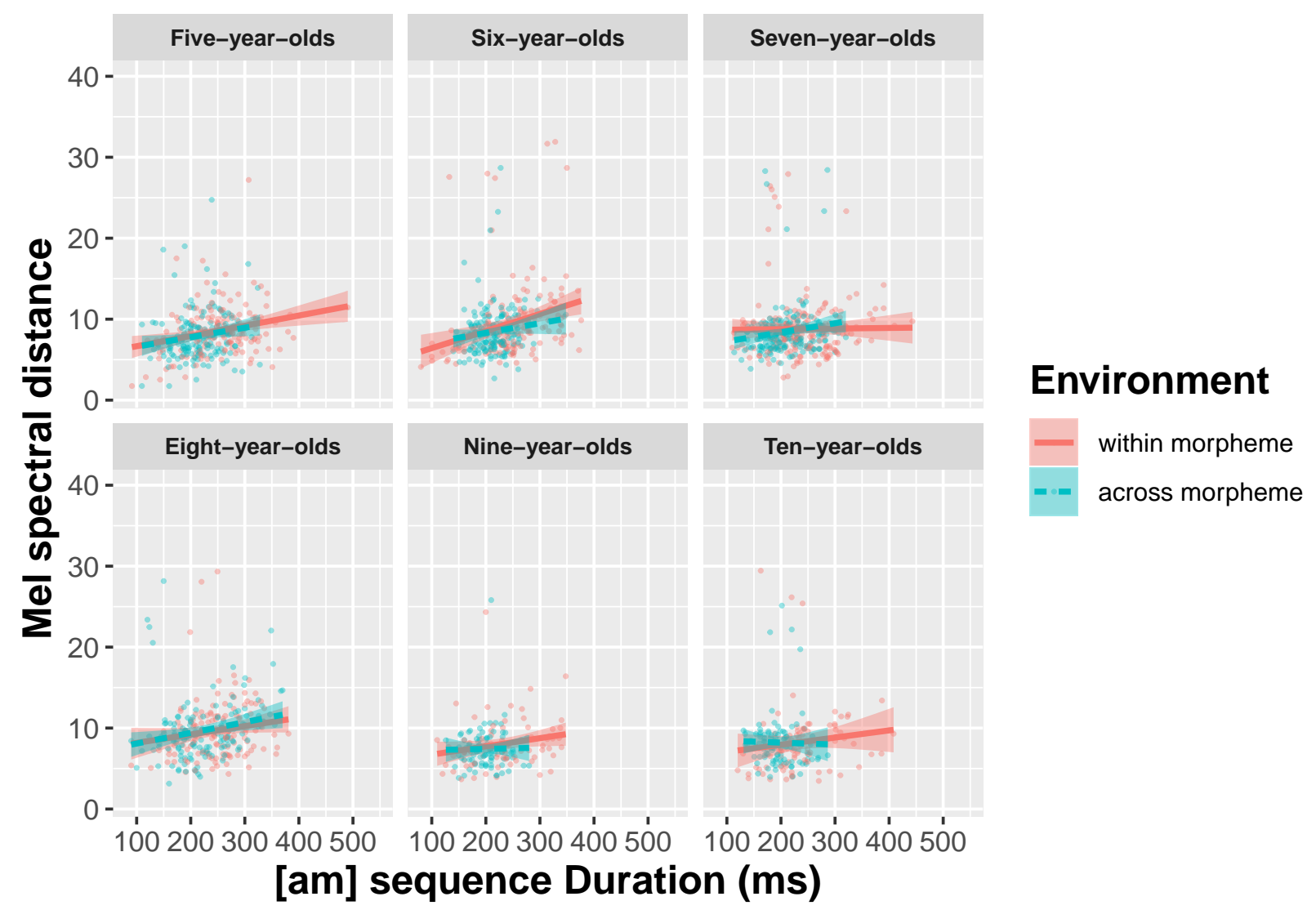

Figure 4. Coarticulation within $[\mathrm{am}]$ by sequence duration, morphological environment, and age in child speakers

in duration than within morpheme sequences for the children.

\subsection{Compensatory shortening}

One finding that emerged from the modeling in the previous section was a different effect of word length on coarticulation between the adults and children. The degree of children's coarticulation tended to progressively increase in words with more syllables; no such pattern was apparent for the adults.

An exploratory analysis was conducted to explain the different relationship between coarticulation and word length for adults and children. This analysis asks, does the direction of the relationship between word length and coarticulation also hold for duration? Since coarticulation and duration are negatively correlated, this analysis predicts that duration would decrease as a function of the number of syllables in a word for children. As such, the children's productions would reflect the phenomenon of Compensatory SHortening (also known as polysyllabic shortening), or the tendency for segment durations to shorten in longer-duration and/or polysyllabic words (Harrington, Kleber, Reubold, and Siddins 2015, Lehiste and Shockey 1972, Munhall, Fowler, Hawkins, and Saltzman $1992)$. 
An effect of word length upon duration was predicted for the adults as well. However, just as it was found that coarticulation did not increase as a function of word length in the adult model, it is anticipated that adults likewise will not compensate durationally for longer words. As a result, the children, but not the adults, would exhibit compensatory shortening during their word production.

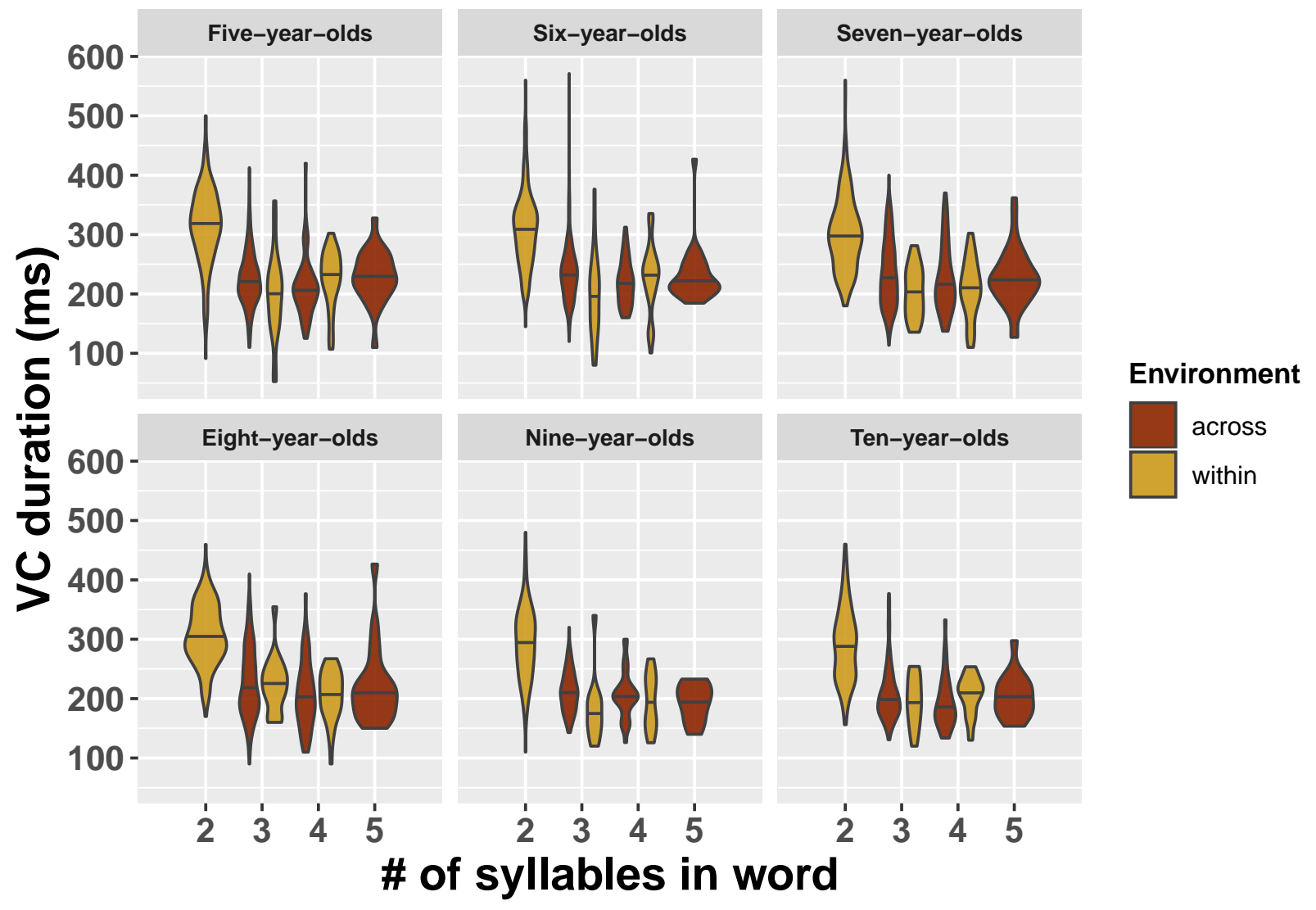

Figure 5. Sequence duration by word length and word environment: Children

To test the effect of word length (in syllables) upon duration, two linear mixed effects models (adult and child) were fit to predict VC sequence duration (no skewed or non-negative predictors were included in the modeling so GLMMs were not necessary). Model fitting occurred as before in a forward-testing manner: the base model contained random slopes of individual Speaker by Word. Then, parameters were added in the following order: Age Group (fit with weighted effect coding; only included in the child model), VC sequence, Number of Syllables (2-5), and Environment (across versus within). Only the predictors Number of Syllables, Age Group, and VC sequence improved baseline model fit (see Table 7 for the child model summary and Table 8 for the adult model summary; see Appendices $\mathrm{G}$ and $\mathrm{H}$ for tables with descriptive statistics of duration by age and number of syllables).

In both model summaries, the positive beta coefficients for $\mathrm{VC}$ sequence indicate that the [ap] sequence was significantly longer than the [am] sequence (as previous models demonstrated). The insignificance of Environment suggests that that the relationship between duration and word length is independent of word environment. The 
Table 7

Model predicting VC duration: children

Intercept

Age:6

Age:7

Age:8

Age:9

Age:10

VC sequence:[ap]

Two syllables

Three syllables

Four syllables
$230.96^{* * *}$

$(228.03,233.88)$

$8.66^{* * *}$

$(4.74,12.58)$

$3.78^{*}$

$(0.43,7.12)$

0.25

$(-4.26,4.76)$

$-14.46^{* * *}$

$(-20.31,-8.61)$

$-17.23^{* * *}$

$(-22.92,-11.54)$

$28.31^{* * *}$

(24.38, 32.23)

$57.70^{* * *}$

$(54.37,61.03)$

$-21.63^{* * *}$

$(-23.54,-19.72)$

$-33.27^{* * *}$

$(-37.97,-28.56)$

Observations

Log Likelihood

3,877

$-20,476.84$

$40,977.68$

$41,052.84$

Bayesian Inf. Crit.

$41,052.84$

Note: $\quad{ }^{*} \mathrm{p}<0.05 ;{ }^{* *} \mathrm{p}<0.01 ;{ }^{* * *} \mathrm{p}<0.001$ 


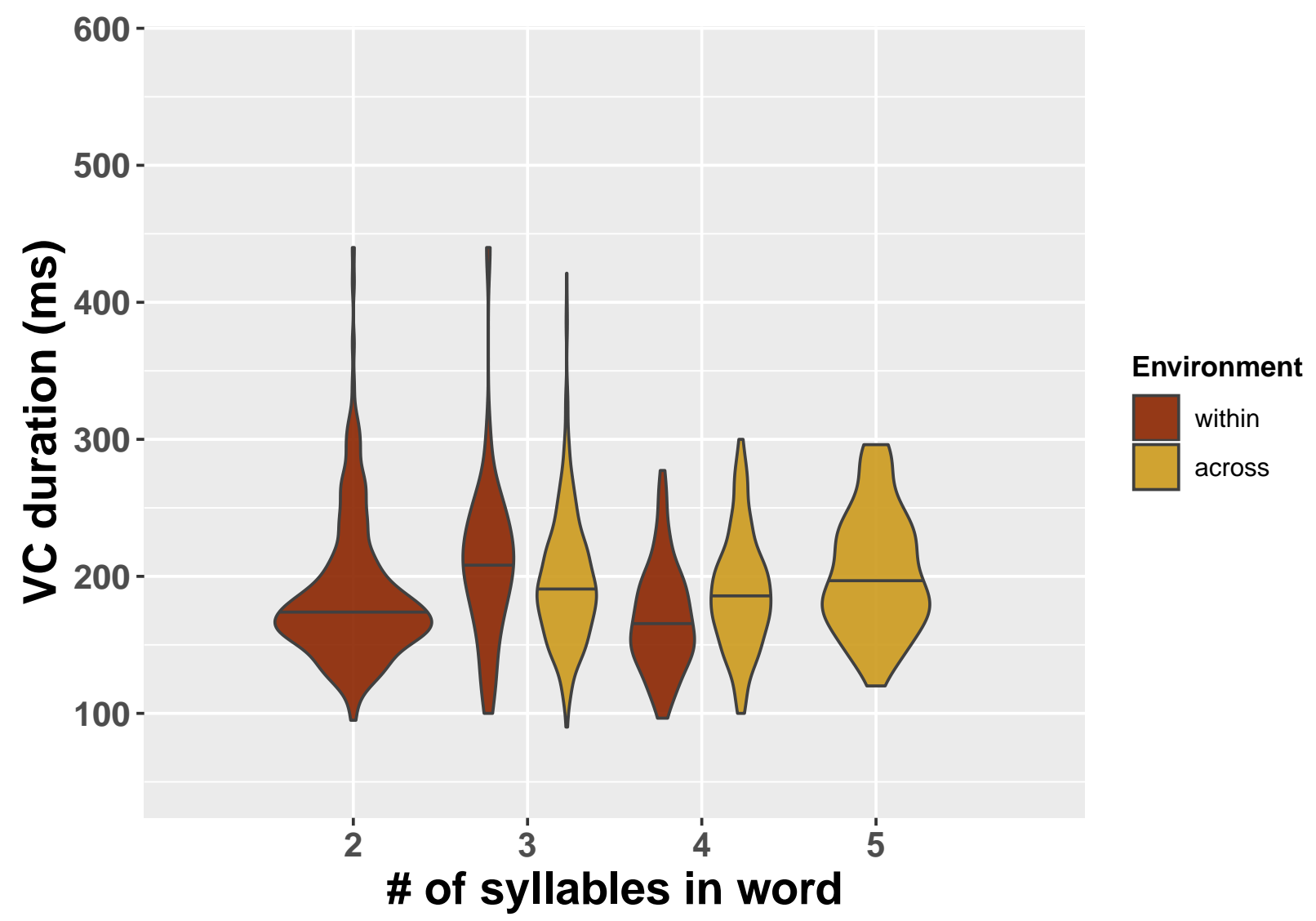

Figure 6. Sequence duration by word length and word environment: Adults

patterns by child age again demonstrate how older children speak faster than younger. Negative coefficients for the nine- and ten-year old children indicate that those children's VC sequences were approximately $14 \mathrm{~ms}$ and $17 \mathrm{~ms}$ shorter, respectively, than the weighted age group mean.

The primary parameter of interest is Syllable Count. In the child model, the positive coefficient for '2 syllable' stimuli indicates that $\mathrm{VC}$ sequence duration in two syllable words was approximately $58 \mathrm{~ms}$ longer than the weighted mean word length. The negative coefficients for the ' 3 syllable' $(\beta=-21.63)$, ' 4 syllable' $(\beta=-33.27)$ and ' 5 syllable' ( $\beta=-28.62$; not presented in model summary) stimuli indicate that VC sequences tend to become shorter in longer words. The diverse stimuli in the two- and three-syllable conditions in particular (many different word types) suggest that this relationship by word length is relatively robust for the children. The only exception to the tendency to shorten sequences in larger words was that [ap] sequences are slightly longer in duration in 5-syllable words than 4-syllable words. However, in this exploratory analysis, the differences between the four and five syllable words were not tightly controlled: there were only two different five-syllable word stimuli: hatun mama-man "grandmother-ALL" and hatun mama-pi 'grandmother-LOC'. We can only speculate that this relationship between sequence duration and number of syllables is strictly linear and would generalize to additional words with more syllables for the children.

For the adult model, Syllable Count only marginally improved over one without $\left(\chi^{2}=6.72, \mathrm{df}=4,7, \mathrm{p}=.08\right)$. 
Table 8

Model predicting VC duration: adults

\begin{tabular}{lc}
\hline \hline Intercept & $174.41^{* * *}$ \\
& $(169.18,179.63)$ \\
VC sequence:[ap] & $29.66^{* * *}$ \\
& $(22.49,36.83)$ \\
Two syllables & -6.12 \\
& $(-13.46,1.23)$ \\
Three syllables & $4.24^{*}$ \\
& $(0.78,7.70)$ \\
Four syllables & -5.36 \\
& $(-12.97,2.25)$ \\
\hline Observations & 1,200 \\
Log Likelihood & $-6,133.52$ \\
Akaike Inf. Crit. & $12,281.04$ \\
Bayesian Inf. Crit. & $12,316.67$ \\
\hline \hline Note: & ${ }^{*} \mathrm{p}<0.05 ;{ }^{* *} \mathrm{p}<0.01 ;{ }^{* * *} \mathrm{p}<0.001$ \\
\end{tabular}

Furthermore, only one level of Syllable Count, the three syllable stimuli, significantly predicted sequence duration.

This result suggests that 1) word length was not strongly predictive of sequence duration in the adults and 2) adults did not compensate for word length by shortening syllable durations in longer words.

In sum, children appear to compensate for word length in their speech production via coarticulation and duration. Word length is also reflected in the adults' speech patterns, but not in any linear direction that suggests compensatory shortening. Causes behind these age differences are proposed in the Discussion.

\section{Discussion}

This study measured the relationship between coarticulation and duration by morphological environment in adult and child Quechua speech. Two questions were posed: 1) how would the coarticulation-duration relationship manifest in child versus adult speech and over the course of development? and 2) would the coarticulation-duration relationship between morphological environments manifest differently by age? The justification for these questions was that overall, children are believed to coarticulate more than adults (Nittrouer et al. 1989 , Noiray, Wieling, et al. 2019 Zharkova et al. 2014; Zharkova et al. 2018), though how this interacts with their slower speaking rate has been unclear. Furthermore, little is known about how coarticulation is reflected in different morphological environments in child speech (cf. Song, Demuth, Shattuck-Hufnagel, and Ménard 2013). 
For the first question, when factoring in speaking rate, children overall coarticulated less than adults. This is likely attributable to adults' faster speaking rate, since adults reliably coarticulate more in faster speech, a point that is elaborated upon in the following sections. Thus, one important takeaway from this work is that speaking rate must be factored into developmental studies of coarticulation as it has the potential to explain large amounts of age-related variability.

Concerning the second question, results confirmed that adult and child speakers differentiated by word environment in their speech. However, the two groups differentiated by environment in distinct ways. Adults reliably coarticulated more in shorter-duration sequences in all combinations of VC sequence and word environment suggesting that they have one, overarching articulatory plan. Differentiation by morphological environment in adult speech hinged on the strength (i.e., the slope) of the relationship between duration and coarticulation. Children instead differentiated by environment via duration ([am] sequences) or the relationship between coarticulation and duration ([ap] sequences). Thus, the children's patterns were simultaneously distinct from and similar to the adults'.

\subsection{Coarticulation-duration differences by age and morphological environment}

Both adults and children showed a broadly similar positive relationship between coarticulation and duration, which is expected given evidence that 1) adult speakers coarticulate more in faster speech Agwuele et al. 2008, Gay 1981. Matthies et al. 2001) and 2) it was not clear that children's slower speaking speed would change the nature of the coarticulation-duration relationship. The children in this study did speak slower than the adults: the average VC sequence duration for the adults was just $192 \mathrm{~ms}(\sigma=47)$ compared to $252 \mathrm{~ms}(\sigma=69)$ for the five-year-olds, 255 $\mathrm{ms}(\sigma=70)$, for the eight-year-olds, and $231 \mathrm{~ms}(\sigma=63)$ for the ten-year-olds. Yet the fact that even the youngest children demonstrated this expected coarticulation-duration relationship in most of their data (with the exception of [ap] between morphemes) suggests the direction of the relationship between the two speech measures is consistent across different speech speeds and over development. Children also seem to acquire it by age 5, if not sooner.

Adults distinguished between word environments in their speech: they used a combination of duration and coarticulation as they consistently coarticulated more in shorter-duration sequences. All child speakers (5-10 years) also differentiated by word environment in their speech. The manifestation of word structure in spoken language thus does not change over development since children as young as five appeared to have awareness of morphological boundaries. However, the children's patterns by word environment differed from the adults'. In slower speech, adult speakers coarticulated less, both across and within morphemes. In children, the same relationship between VC sequence duration and coarticulation appeared in the within-morpheme condition where children coarticulated less when they spoke slower. However, unexpectedly, the children coarticulated more in longer duration [ap] sequences.

The unexpected pattern for [ap] between morphemes warrants exploration. Why did children coarticulate more in longer-duration [ap] sequences? The effect is robust across all word types in the condition (Appendix F), and 
all child age groups (Figure 3), suggesting that neither word frequency nor language experience within the children explain the pattern. So there must be one or more overarching differences between the adults and children, besides age and its accompanying vocabulary growth and lexical reorganization (Lorge \& Chall 1963), that could explain the [ap] pattern. Section 6.3 proposes one such explanation: Quechua language dominance.

Language dominance differences between the adults and children do not, however, explain why the children showed the expected coarticulation-duration relationship for [am] but not [ap]. The data show that the children have acquired the adult-like speech plan of increased coarticulation in faster speech for most combinations of VC sequence and morphological environment. There are two reasons why they may not have acquired it for [ap] across morphemes. First, - $p i$, the locative morpheme used to elicit the across-morpheme [ap] condition, could be less frequent than the allative - man morpheme in Quechua. As a result, children may have less experience inflecting words with - pi so they have not yet acquired the adult-like speech plan for the across-morpheme environment. However, if it were a matter of developmental experience with the morpheme, we might expect the nine- or ten-year-old children to show more adult-like speech plans. Instead, they exhibit some of the sharpest slopes of coarticulation by duration for this condition.

An additional, complementary reason for the children's [ap] pattern across morphemes could be phonotactic probability. The VC sequences' surrounding environments are not equally probable. The surrounding environment for [am], [ama], like in the across-morpheme items papa-man 'potato-ALL' or t'ika-man 'flower-MAN' and the withinmorpheme item mama 'mom' is more frequent than [api] in both Quechua and Spanish. So, the bilingual children gain more experience with [ama] because it is frequent in both languages. The [api] context is less frequent overall, and especially in an across-morpheme environment which would only apply in Quechua, leading children to have an immature speech plan for [ap] across morphemes.

Again, if either morpheme frequency or phonotactic probability explained the children's [ap] pattern, the lack of developmental differences by child age would still be surprising. However, when the language dominance of the children is considered, as the following section outlines in more detail, perhaps at least the reflection of Spanish language phonotactics in the children's Quechua speech even at older ages is to be expected.

\subsection{Compensatory shortening}

A post-hoc, exploratory analysis in this study showed that children, but not adults, compensated for word length by shortening VC sequences in longer words in the phenomenon of compensatory shortening (Harrington et al. 2015 Lehiste 1972 Munhall et al. 1992..$^{2}$ The children's compensatory shortening reinforces previous work, conducted on adult speech, that has demonstrated how roots can have different variants in their bound and free forms (Kemps, Wurm, Ernestus, Schreuder, \& Baayen 2005) because the prosodically-longer stimuli were often bound forms of free roots (e.g., bound root llama-pi 'llama-LOC' and free root llama 'llama'). One challenge in 
the study of morphophonetics has been to identify the explanatory mechanisms behind morphologically-conditioned speech variation; at least in the child data, compensatory shortening could be one of these mechanisms.

This relationship between word size and segment duration in the children's speech is notable. The data indicate that the children could have some minimal planning unit size causing them to elongate prosodically short words (or shorten prosodically long words) to fit within the unit's temporal domain. However, possibly even more interesting than the children's patterns is the lack of compensatory shortening in the adults because previous findings on compensatory shortening came from adult populations. Why don't adults in the current study compensate for word size in their speech production as the children appear to?

\subsection{Explaining differences between adults and children}

Two differences between adult and child speech patterns have emerged in the Discussion: 1) children, but not adults, coarticulate more in longer-duration, across-morpheme [ap] sequences and 2) children, but not adults, compensate temporally for word length. One explanation for the compensatory shortening difference is that adults speak faster than children, leading to more extreme phonetic reduction. Children do not approximate adult-like speaking rates until early puberty (Lee et al.1999 Smith 1992), a pattern replicated in the present study (see Tables 3 and 4). Speaking rate is relevant for compensatory shortening because adult Quechua speakers may speak so much faster, and reduce so much more, than children that there could be insufficient freedom in their speech duration to differentiate sequence duration by prosodic word size. Speakers reduce significantly more in fast speech compared to slower, controlled speech. In fast speech, the vowel space is smaller and more centralized (Fourakis 1991; Tsao, Weismer, and Iqbal 2006) - which may compromise contrasts (Koopmans-Van Beinum 1980), increase coarticulation between phones (Agwuele et al. 2008; Matthies et al. 2001), and cause the omission of entire segments or syllables (Johnson 2004). For the current study, the durational data by age suggest that all adult speech, regardless of prosodic or morphological structure, is maximally fast and reduced.

Though there is little work on the phonetics of highly morphologically complex languages, the author can anecdotally attest to how speaking rate interplays with Quechua word structure. Just as the orthographic forms of English words rarely correspond to their phonetic realization in fast, spontaneous speech, spoken Quechua words deviate from their citation form. In Quechua, this is especially true with large words that contain numerous suffixes, where the most extreme reduction can be seen. The further a suffix is found from the root in Quechua, the more likely it is to be reduced. The explanation for this is partially aerodynamic (e.g., airflow), but there are likely perceptual and information-theoretic explanations. When suffixes are highly reduced compared to stems, speakers can more easily demarcate between them, and identify word boundaries (Zingler 2018). Furthermore, word meanings are likely increasingly predictable as additional suffixes are added and the available semantic space of the word narrows. ${ }^{3}$ Variability in the phonetic realization of English morphology is dependent upon the predictability of plurality given 
the sentence frame (Cohen 2014), so it is possible that speakers likewise make probability calculations over multiple suffixes. Though more work is needed to understand probabilistic reduction based on word structure, one explanation for adults' lack of compensatory lengthening is speaking rate and phonetic reduction.

A second explanation for the lack of compensatory shortening in adults is that the adults are more dominant in Quechua than the children. The adults' greater Quechua dominance may also explain the unexpected coarticulationduration relationship in children's [ap] sequences. First, this means that the adults may speak faster and, again, may be unable to temporally differentiate prosodic structures. It also means that the adults are more likely to have uniform, established articulatory speech plans in Quechua because they use the language more. The adults studied here reliably coarticulate more in faster speech. It would not be surprising if the children, who have less Quechua experience, had not yet established reliable speech plans for all word environments and phone sequences in Quechua.

Recent changes in Bolivia's educational policy, as well as the country's general sociolinguistic situation, may have led to adults' increased Quechua dominance. Bilingual education in Bolivia became mandatory in 1994 and has, in theory, been relatively widespread since the early 2000s (Benson 2004). This means more children are attending and completing more schooling than ever before (Hornberger 2009$)$.

In practice, however, bilingual education often takes the form of Spanish-only classrooms. In Quechua-speaking areas, many trained teachers do not speak Quechua fluently or are not provided with Quechua teaching materials and textbooks. The result - students completing more schooling instructed in Spanish—has been rapid language shift (Hornberger \& King 1996). This is apparent even within the last decade, as the first generation of women educated in this system are now raising their children using both Quechua and Spanish, instead of monolingual Quechua, in an increasingly Spanish-dominant environment.

These sociolinguistic dynamics could manifest here as the adult participants (many of whom are mothers) may be more Quechua-dominant than some of the children. Though the adults who participated were only, on average, 13 years older than the eldest children, and all adults and children identified as bilingual, their language practices may reflect recent changes in educational policy. All of the children here also attended school, in Spanish, for 3-4 hours per day. However, only one of the adult females was still attending school, which could also explain differences by age.

This explanation may not entirely explain the differences between the adult and child Quechua speakers. For one thing, previous studies on compensatory shortening (Lehiste 1972, Munhall et al. 1992) reported on highly-fluent, monolingual adult speakers who did compensate for prosodic structure. Also, if increased language experience with Quechua predicts uniform articulatory strategies, then we might anticipate that ten-year-olds would have more uniform strategies than five-year-olds. However, these clear differences in language usage and experience between adults and children, independent of age, may explain some of the speech production differences observed between the groups. 


\subsection{Effects of bilingual status}

Given that all participants were bilingual, Spanish use and contact may play a role in these results. First, although participants were not literate in Quechua, the children were becoming literate in Spanish. Nevertheless, it is unlikely that Spanish literacy would translate to increased morphological awareness in Quechua given Spanish and Quechua's distinct morphological typologies. Quechua is more synthetic than Spanish (words tend to carry more unique morphemes). Spanish is also highly fusional while Quechua is strictly agglutinating - each morpheme carries a unique grammatical role. The typological distance between the languages is unlikely to facilitate much crossover awareness of word structure, be it prosodic or morphological.

Beyond literacy, the children's bilingual Quechua-Spanish status could increase between-subject variability. This study did not report participants' bilingual language dominance, but all speakers reported using both languages. (All children in Bolivia acquire Spanish in school making a more controlled sample of monolingual school-aged children difficult to find.) The decision not to conduct a traditional language usage survey was made for several reasons. Traditional measures of self-reported bilingual dominance, such as the bilingual language profile Birdsong, Gertken, \& Amengual 2012), often rely on participant literacy or familiarity and comfort with written behavioral research surveys. Also, the traditional stigmatization of indigenous languages in Bolivia may render self-reports of language dominance unreliable. Nevertheless, bilingual children are rarely exposed to or use equal quantities of their two languages (Orena, Byers-Heinlein, \& Polka 2020). Naturalistic assessments of the child Quechua-Spanish speakers' bilingual language practices has been reported elsewhere (Cychosz 2020a); results showed that there is variability in the amount of Spanish and Quechua that the children use. These individual differences even explained some variability in the children's coarticulation patterns. Consequently, one difference between speakers that was not explored in this study is bilingual Quechua-Spanish language use.

\subsection{Future work}

Future work is needed to further explore relationships between coarticulation, duration, and word structure. Going forward, researchers may also benefit from the use of articulatory measures. Given the logistics of ultrasound imaging, and the limitations of fieldwork, the current study was not able to collect articulatory data, which would otherwise be a valuable addition.

An important caveat to this study is that the data elicitation techniques differed between adults and children. The children produced the target words in response to a wh-question while the adults embedded the words in a carrier phrase. This is relevant since the children, in their response to the question, may have emphasized the target words more than the adults. Known correlates of speech emphasis include heightened f0, amplitude, and, most importantly for the current study, a slower speaking rate. While it seems unlikely that the data elicitation technique fully explained the children's slower speaking rates observed in this study - most work finds that children 
speak slower than adults - the data elicitation differences could have magnified the observed speaking rate differences between adults and children.

A notable difference between the adults and children studied concerned [ap] in the across-morpheme condition: adults coarticulated more in faster speech but children, contrary to their patterning in all other combinations of sequence and morphological environment, coarticulated less. This was robust across word types. Children might reliably coarticulate less in faster speech in additional environments, or maybe for all V-plosive combinations. This is unclear because the stimuli in this work emphasized lexical diversity, instead of phonemic, so only two VC sequences were included. Going forward, additional studies on children's coarticulation, duration, and/or the interaction of speech with morphological structure need to include phonemic diversity because there appear to be phoneme-specific effects in the children's speech patterning.

\section{Conclusion}

This study measured adult and child Quechua speakers' coarticulation-duration patterns within morphemes and across morpheme boundaries. Contrary to much previous research on the topic, the children coarticulated less than adults, a finding that was attributed to adults' faster speaking rate, suggesting that future cross-sectional studies on coarticulatory development should factor in speaking rate. Concerning speech patterns by morphological environment, adults and children alike employed a combination of coarticulatory and temporal cues to distinguish between the within- and across-morpheme environments, but they did so in distinct ways. This finding of speech production differences by environment replicated previous findings on child speech production patterns by word environment but in an understudied, morphologically complex language. Finally, the children showed increased prosodic sensitivity where the adults did not: children shortened the duration of sequences in prosodically longer words. It was suggested that these differences between adults and children were attributable to adults' faster speaking rate and their increased Quechua use. Overall, results demonstrate the importance of extending studies on phonetic development to speakers with different language backgrounds and languages with different structures.

\section{Declaration of interest}

The author has no competing interests to report.

\section{Acknowledgements}

The author wishes to thank all the participating children, as well as their families and teachers, for their patience and willingness to participate in this research program. This paper benefited from many discussions with Keith Johnson, Sharon Inkelas, Mahesh Srinivasan, and Alex Cristia. Jan Edwards additionally helped develop the morphological elicitation task. The author acknowledges financial support from two Oswalt Endangered Language 
grants and the Raymond H. Stetson Scholarship in Phonetics and Speech Science.

\section{Footnotes}

${ }^{1}$ To further ensure that the difference by Environment was due to morphological structure, all models were additionally fit with the covariate Word Duration (in ms), instead of Syllable Count (models were not fit with both since Word Duration and Syllable Count are highly correlated). Results were broadly the same: the three-way interaction of Sequence duration, VC sequence, and Environment improved upon model fits controlling for Word Duration with the same direction of the effect. Like the models that control for prosodic structure with the covariate, Syllable Count, these models also suggest that the speech production differences by word environment were more likely morphological, not prosodic, in nature.

${ }^{2}$ The term compensatory shortening is also variably used in the literature to refer to shortening of stressed vowels compared to unstressed vowels in the context of polysyllabicity (Harrington et al. 2015), or the shortening of stressed vowels in the context of unstressed vowels and consonants (Fowler 1981).

${ }^{3}$ For English, however, Plag and Baayen (2009) found that those suffixes farthest from the stem are also the most productive and available for use in novel environments. 


\section{References}

Agwuele, A., Sussman, H. M., \& Lindblom, B. (2008). The Effect of Speaking Rate onConsonant Vowel Coarticulation. Phonetica, 65(4), 194-209. doi: 10.1159/000192792

Aust, F., \& Barth, M. (2018). Papaja:Create APA manuscripts with R Markdown.

Barbier, G., Perrier, P., Ménard, L., Payan, Y., Tiede, M. K., \& Perkell, J. S. (2013). Speech planning as an index of speech motor control maturity. In Proceedings of Interspeech 2013. Lyon, France.

Barbier, G., Perrier, P., Ménard, L., Payan, Y., Tiede, M. K., \& Perkell, J. S. (2015). Speech planning in 4-yearold children versus adults: Acoustic and articulatory analyses. In Proceedings of Interspeech 2015. Dresden, Germany.

Bates, D., Maechler, M., Bolker, B., \& Walker, S. (2015). Fitting linear mixed-effects models using lme4. Journal of Statistical Software, 67(1), 1-48.

Benson, C. (2004). Bilingual schooling in Mozambique and Bolivia: From experimentation to implementation. Language Policy, 3(1), 47-66. doi: 10.1023/B:LPOL.0000017725.62093.66

Birdsong, D., Gertken, L. M., \& Amengual, M. (2012). Bilingual Language Profile: An Easy-to-Use Instrument to Assess Bilingualism. COERLL, University of Texas at Austin.

Boersma, P., \& Weenink, D. (2020). Praat: Doing phonetics by computer.

Bradlow, A. R. (2002). Confluent talker- and listener-oriented forces in clear speech production. In C. Gussenhoven \& N. Warner (Eds.), Laboratory Phonology (Vol. 7, pp. 241-273). Berlin and New York: Mouton de Gruyter.

Brooks, M. E., Kristensen, K., van Benthem, K. J., Magnusson, A., Berg, C. W., Nielsen, A., ... Bolker, B. M. (2017). glmmTMB balances speed and flexibility among packages for zero-inflated generalized linear mixed modeling. The R Journal, 9(2), 378-400.

Chen, W.-R., Whalen, D. H., \& Shadle, C. H. (2019). F0-induced formant measurement errors result in biased variabilities. The Journal of the Acoustical Society of America, 145(5), EL360-EL366. doi: 10.1121/1.5103195

Cho, T. (2001). Effects of Morpheme Boundaries on Intergestural Timing: Evidence from Korean. Phonetica, 58(3), 129-162. doi: 10.1159/000056196

Cohen, C. (2014). Probabilistic reduction and probabilistic enhancement: Contextual and paradigmatic effects on morpheme pronunciation. Morphology, 24(4), 291-323. doi: 10.1007/s11525-014-9243-y

Courtney, E. H., \& Saville-Troike, M. (2002). Learning to construct verbs in Navajo and Quechua. Journal of Child Language, 29(03), 623-654. doi: 10.1017/S0305000902005160

Cychosz, M. (2020a). Phonetic development in an agglutinating language (Unpublished doctoral dissertation ed.). Berkeley, CA: University of California.

Cychosz, M. (2020b). Word structure in early Quechua speech: Morphology and acoustic phonetics (Open Science 
Framework Project).

Cychosz, M., Edwards, J. R., Munson, B., \& Johnson, K. (2019). Spectral and temporal measures of coarticulation in child speech. The Journal of the Acoustical Society of America-Express Letters, 146(6), EL516-EL522. doi: $10.1121 / 1.5139201$

Cychosz, M., Munson, B., \& Edwards, J. R. (to appear). Practice and experience predict coarticulation in child speech. Language, Learning and Development.

Davis, M., \& Redford, M. A. (2019). The Emergence of Discrete Perceptual-Motor Units in a Production Model That Assumes Holistic Phonological Representations. Frontiers in Psychology, 10(2121), 1-19. doi: 10.3389/ fpsyg.2019.02121

Fenson, L., Marchman, V., Thal, D. J., Dale, P., Reznick, J., \& Bates, E. (2007). MacArthur-Bates Communicative Development Inventories User's Guide and Technical Manual (2nd Edition ed.). San Diego, CA: Singular.

Flege, J. E. (1988). Anticipatory and carry-over nasal coarticulation in the speech of children and adults. Journal of Speech Language and Hearing Research, 31, 525-536.

Fourakis, M. (1991). Tempo, stress, and vowel reduction in American English. The Journal of the Acoustical Society of America, 90(4), 1816-1827. doi: 10.1121/1.401662

Fowler, C. A. (1981). A Relationship between Coarticulation and Compensatory Shortening. Phonetica, 38(1-3), 35-50. doi: 10.1159/000260013

Gallagher, G. (2016). Vowel height allophony and dorsal place contrasts in Cochabamba Quechua. Phonetica, 73(2), $101-119$.

Gavrilov, I., \& Pusev, R. (2014). Normtest: Tests for Normality.

Gay, T. (1981). Mechanisms in the control of speech rate. Phonetica, 38, 148-158.

Gerosa, M., Lee, S., Giuliani, D., \& Narayanan, S. (2006). Analyzing children's speech: An acoustic study of consonants and consonant-vowel transition. In 2006 IEEE International Conference on Acoustics Speed and Signal Processing Proceedings (Vol. 1, pp. 393-396). Toulouse, France: IEEE. doi: 10.1109/ICASSP.2006 .1660040

Goffman, L., Smith, A., Heisler, L., \& Ho, M. (2008). The Breadth of Coarticulatory Units in Children and Adults. Journal of Speech Language and Hearing Research, 51 (6), 1424-1437. doi: 10.1044/1092-4388(2008/07-0020)

Goodell, E. W., \& Studdert-Kennedy, M. (1992). Acoustic Evidence for the Development of Gestural Coordination in the Speech of 2-Year-Olds: A Longitudinal Study. Haskins Laboratories Status Report on Speech Research, SR-111/1123, 63-88.

Harrington, J., Kleber, F., Reubold, U., \& Siddins, J. (2015). The relationship between prosodic weakening and sound change: Evidence from the German tense/lax vowel contrast. Laboratory Phonology, 6(1). doi: 10.1515/ lp-2015-0002 
Hay, J. (2003). Causes and Consequences of Word Structure. New York and London: Routledge.

Hlavac, M. (2018). Stargazer: Well-Formatted Regression and Summary Statistics Tables. Bratislava, Slovakia: Central European Labour Studies Institute (CELSI).

Hoff, E. (2003). The Specificity of Environmental Influence: Socioeconomic Status Affects Early Vocabulary Development Via Maternal Speech. Child Development, 74(5), 1368-1378. doi: 10.1111/1467-8624.00612

Hornberger, N. H. (2009). Multilingual education policy and practice: Ten certainties (grounded in Indigenous experience). Language Teaching, 42(2), 197-211. doi: 10.1017/S0261444808005491

Hornberger, N. H., \& King, K. A. (1996). Language Revitalisation in the Andes: Can the Schools Reverse Language Shift? Journal of Multilingual and Multicultural Development, 17(6), 427-441. doi: 10.1080/ 01434639608666294

Johnson, K. (2004). Massive reduction in conversational American English. In K. Yoneyama \& K. Maekawa (Eds.), Proceedings of the 1st session of the 10th International Symposium (pp. 29-54). The National International Institute for Japanese Language.

Katz, W. F., Kripke, C., \& Tallal, P. (1991). Anticipatory coarticulation in the speech of adults and young children: Acoustic, perceptual, and video data. Journal of Speech Language and Hearing Research, 34, 1222-1232.

Kemps, R. J. J. K., Wurm, L. H., Ernestus, M., Schreuder, R., \& Baayen, R. H. (2005). Prosodic cues for morphological complexity in Dutch and English. Language and Cognitive Processes, 20(1-2), 43-73. doi: $10.1080 / 01690960444000223$

Kent, R. D. (1983). The Segmental Organization of Speech. In P. F. MacNeilage (Ed.), The Production of Speech (pp. 57-89). New York, NY: Springer New York. doi: 10.1007/978-1-4613-8202-7_4

Koopmans-Van Beinum, F. J. (1980). Vowel contrast reduction, an acoustic and perceptual study of Dutch vowels in various speech conditions. Amsterdam: University of Amsterdam, Academische Per B.V.

Kuznetsova, A., Brockhoff, P., \& Christensen, R. (2017). lmerTest Package: Tests in linear mixed-effects models. Journal of Statistical Software, 82(13), 1-26.

Lee, S., Potamianos, A., \& Narayanan, S. (1999). Acoustics of children's speech: Developmental changes of temporal and spectral parameters. The Journal of the Acoustical Society of America, 105(3), 1455-1468. doi: 10.1121/ 1.426686

Lee-Kim, S.-I., Davidson, L., \& Hwang, S. (2013). Morphological effects on the darkness of English intervocalic /1/. Laboratory Phonology, 4(2), 475-511. doi: 10.1515/lp-2013-0015

Lehiste, I. (1972). The Timing of Utterances and Linguistic Boundaries. The Journal of the Acoustical Society of America, 51(6B), 2018-2024. doi: 10.1121/1.1913062

Lehiste, I., \& Shockey, L. (1972). On the perception of coarticulation effects in English VCV syllables. Journal of Speech and Hearing Research, 15(3), 500-506. 
Liceralde, V. R. T. (2018). Consequences of power transformation in linear mixed-effects models of chronometric data (Unpublished doctoral dissertation). University of North Carolina, Chapel Hill, Chapel Hill, NC.

Lo, S., \& Andrews, S. (2015). To transform or not to transform: Using generalized linear mixed models to analyse reaction time data. Frontiers in Psychology, 6(1171), 1-16. doi: 10.3389/fpsyg.2015.01171

Lorge, I., \& Chall, J. (1963). Estimating the Size of Vocabularies of Children and Adults: An Analysis of Methodological Issues. The Journal of Experimental Education, 32(2), 147-157. doi: 10.1080/00220973.1963.11010819

Matthies, M., Perrier, P., Perkell, J., \& Zandipour, M. (2001). Variation in Anticipatory Coarticulation With Changes in Clarity and Rate. Journal of Speech Language and Hearing Research, 44(2), 340-353.

McAuliffe, M., Socolof, M., Mihuc, A., Wagner, M., \& Sonderegger, M. (2017). Montreal Forced Aligner.

McFee, B., Raffel, C., Liang, D., Ellis, D., McVicar, M., Battenberg, E., \& Nieto, O. (2015). Librosa: Audio and Music Signal Analysis in Python. In Proceedings of the 14th Python in science conference (pp. 18-24). Austin, Texas. doi: 10.25080/Majora-7b98e3ed-003

Munhall, K., Fowler, C., Hawkins, S., \& Saltzman, E. (1992). "Compensatory shortening" in monosyllables of spoken English. Journal of Phonetics, 20(2), 225-239. doi: 10.1016/S0095-4470(19)30624-2

Muysken, P. (2012a). Contacts between indigenous languages in South America. In L. Campbell \& V. Grondona (Eds.), The indigenous languages of South America: A comprehensive guide (pp. 235-258). Berlin, Germany: Walter de Gruyter.

Muysken, P. (2012b). Spanish affixes in the Quechua languages: A multidimensional perspective. Lingua, 122(5), 481-493.

Nijland, L., Maassen, B., der Meulen, S. V., Gabreëls, F., Kraaimaat, F. W., \& Schreuder, R. (2002). Coarticulation patterns in children with developmental apraxia of speech. Clinical Linguistics \& Phonetics, 16 (6), 461-483. doi: $10.1080 / 02699200210159103$

Nittrouer, S., Studdert-Kennedy, M., \& McGowan, R. S. (1989). The emergence of phonetic segments: Evidence from the spectral structure of fricative-vowel syllables spoken by children and adults. Journal of Speech Language and Hearing Research, 32, 120-132.

Nittrouer, S., Studdert-Kennedy, M., \& Neely, S. T. (1996). How Children Learn to Organize Their Speech Gestures: Further Evidence From Fricative-Vowel Syllables. Journal of Speech Language and Hearing Research, 39, 379389. doi: $10.1044 /$ jshr.3902.379

Noiray, A., Abakarova, D., Rubertus, E., Krüger, S., \& Tiede, M. (2018). How Do Children Organize Their Speech in the First Years of Life? Insight From Ultrasound Imaging. Journal of Speech, Language, and Hearing Research, 61(6), 1355-1368. doi: 10.1044/2018_JSLHR-S-17-0148

Noiray, A., Ménard, L., \& Iskarous, K. (2013). The development of motor synergies in children: Ultrasound and acoustic measurements. Journal of the Acoustical Society of America, 133(1), 444-452. doi: 10.1121/1.4763983 
Noiray, A., Popescu, A., Killmer, H., Rubertus, E., Krüger, S., \& Hintermeier, L. (2019). Spoken Language Development and the Challenge of Skill Integration. Frontiers in Psychology, 10(2777), 1-17. doi: 10.3389/ fpsyg.2019.02777

Noiray, A., Wieling, M., Abakarova, D., Rubertus, E., \& Tiede, M. (2019). Back From the Future: Nonlinear Anticipation in Adults' and Children's Speech. Journal of Speech, Language, and Hearing Research, 62 (8S), 3033-3054. doi: 10.1044/2019_JSLHR-S-CSMC7-18-0208

Öhman, S. E. G. (1966). Coarticulation in VCV Utterances: Spectrographic Measurements. The Journal of the Acoustical Society of America, 39(1), 151-168. doi: 10.1121/1.1909864

Orena, A. J., Byers-Heinlein, K., \& Polka, L. (2020). What do bilingual infants actually hear? Evaluating measures of language input to bilingual-learning 10-month-olds. Developmental Science, 23(2), 1-14. doi: 10.1111/ desc. 12901

Pace, A., Luo, R., Hirsh-Pasek, K., \& Golinkoff, R. M. (2017). Identifying Pathways Between Socioeconomic Status and Language Development. Annual Review of Linguistics, 3(1), 285-308. doi: 10.1146/annurev-linguistics $-011516-034226$

Plag, I. (2014). Phonological and phonetic variability in complex words: An uncharted territory. Rivista di Linguistica, 26(2), 209-228.

Redford, M. A. (2019). Speech Production From a Developmental Perspective. Journal of Speech, Language, and Hearing Research,62(8S), 2946-2962. doi: 10.1044/2019_JSLHR-S-CSMC7-18-0130

Reidy, P. F., Kristensen, K., Winn, M. B., Litovsky, R. Y., \& Edwards, J. R. (2017). The Acoustics of Word-Initial Fricatives and Their Effect on Word-Level Intelligibility in Children With Bilateral Cochlear Implants:. Ear and Hearing, 38(1), 42-56. doi: 10.1097/AUD.0000000000000349

RStudio Team. (2020). RStudio: Integrated Development for R. Boston, MA: RStudio, Inc.

Rubertus, E., \& Noiray, A. (2018). On the development of gestural organization: A cross-sectional study of vowelto-vowel anticipatory coarticulation. PLOS ONE, 13(9), 1-21. doi: 10.1371/journal.pone.0203562

Sereno, J. A., Baum, S. R., Marean, G. C., \& Lieberman, P. (1987). Acoustic analyses and perceptual data on anticipatory labial coarticulation in adults and children. Journal of the Acoustical Society of America, 81(2), $512-519$.

Sereno, J. A., \& Lieberman, P. (1987). Developmental aspects of lingual coarticulation. Journal of Phonetics, 15, $247-257$.

Seyfarth, S., Garellek, M., Gillingham, G., Ackerman, F., \& Malouf, R. (2018). Acoustic differences in morphologically-distinct homophones. Language, Cognition and Neuroscience, 33(1), 32-49. doi: 10.1080/ 23273798.2017.1359634

Shapiro, S. S., Wilk, M. B., \& Chen, H. J. (1968). A Comparative Study of Various Tests for Normality. Journal of 
the American Statistical Association, 63(324), 1343-1372. doi: 10.1080/01621459.1968.10480932

Smith, B. L. (1992). Relationships between duration and temporal variability in children's speech. The Journal of the Acoustical Society of America, 91(4), 2165-2174. doi: 10.1121/1.403675

Song, J. Y., Demuth, K., Evans, K., \& Shattuck-Hufnagel, S. (2013). Durational cues to fricative codas in 2-yearolds' American English: Voicing and morphemic factors. Journal of the Acoustical Society of America, 133(5), 2931-2946. doi: 10.1121/1.4795772

Song, J. Y., Demuth, K., Shattuck-Hufnagel, S., \& Ménard, L. (2013). The effects of coarticulation and morphological complexity on the production of English coda clusters: Acoustic and articulatory evidence from 2-year-olds and adults using ultrasound. Journal of Phonetics, 41, 281-295. doi: 10.1016/j.wocn.2013.03.004

Strycharczuk, P. (2019). Phonetic Detail and Phonetic Gradience in Morphological Processes. In Oxford Research Encyclopedia of Linguistics (pp. 1-25). Oxford University Press. doi: 10.1093/acrefore/9780199384655.013.616

Strycharczuk, P., \& Scobbie, J. M. (2016). Gradual or abrupt? The phonetic path to morphologisation. Journal of Phonetics, 59, 76-91. doi: 10.1016/j.wocn.2016.09.003

Tomaschek, F., Tucker, B. V., Ramscar, M., \& Baayen, R. H. (2019). How is anticipatory coarticulation of suffixes affected by lexical proficiency? (Preprint). PsyArXiv. doi: 10.31234/osf.io/gv89j

Torero, O. (1964). Los dialectos Quechuas. In Anales Cientificos de la Universidad Agraria (Vol. 2, pp. 446-478). Lima, Peru.

Tsao, Y.-C., Weismer, G., \& Iqbal, K. (2006). The effect of intertalker speech rate variation on acoustic vowel space. Journal of the Acoustical Society of America, 119(2), 1074-1082.

Warner, N., Good, E., Jongman, A., \& Sereno, J. (2006). Orthographic vs. morphological incomplete neutralization effects. Journal of Phonetics, 34 (2), 285-293. doi: 10.1016/j.wocn.2004.11.003

Whalen, D. H. (1990). Coarticulation is largely planned. Journal of Phonetics, 18, 3-35.

Whiteside, S., \& Hodgson, C. (2000). Speech patterns of children and adults elicited via a picture-naming task: An acoustic study. Speech Communication, 32(4), 267-285. doi: 10.1016/S0167-6393(00)00013-3

Wickham, H. (2016). Ggplot2: Elegant Graphics for Data Analysis. New York: Springer-Verlag New York.

Zharkova, N., Hardcastle, W. J., \& Gibbon, F. E. (2018). The dynamics of voiceless sibilant fricative production in children between 7 and 13 years old: An ultrasound and acoustic study. The Journal of the Acoustical Society of America, 144 (3), 1454-1466. doi: 10.1121/1.5053585

Zharkova, N., Hewlett, N., \& Hardcastle, W. J. (2011). Coarticulation as an Indicator of Speech Motor Control Development in Children: An Ultrasound Study. Motor Control, 15(1), 118-140. doi: 10.1123/mcj.15.1.118

Zharkova, N., Hewlett, N., Hardcastle, W. J., \& Lickley, R. J. (2014). Spatial and Temporal Lingual Coarticulation and Motor Control in Preadolescents. Journal of Speech Language and Hearing Research, 57(2), 374-388. doi: 10.1044/2014_JSLHR-S-11-0350 
Zingler, T. (2018). Reduction without fusion: Grammaticalization and wordhood in Turkish. Folia Linguistica, 52(2), 415-447. doi: 10.1515/flin-2018-0011 
Appendix A

South Bolivian Quechua Consonant Inventory

\begin{tabular}{l|c|c|c|c|c|c|c} 
& Bilabial & Dental & Postalveolar & Palatal & Velar & Uvular & Glottal \\
\hline Plosive & $\mathrm{p}$ & $\mathrm{t}$ & $\mathrm{f}$ & & $\mathrm{k}$ & $\mathrm{q}$ & \\
\hline Aspirated & $\mathrm{p}^{\mathrm{h}}$ & $\mathrm{t}^{\mathrm{h}}$ & $\mathrm{f}^{\mathrm{h}}$ & & $\mathrm{k}^{\mathrm{h}}$ & $\mathrm{q}^{\mathrm{h}}$ & \\
\hline Ejective & $\mathrm{p}^{\prime}$ & $\mathrm{t}^{\prime}$ & $\mathrm{tg}^{\prime}$ & & $\mathrm{k}^{\prime}$ & $\mathrm{q}^{\prime}$ & \\
\hline Nasal & $\mathrm{m}$ & $\mathrm{n}$ & & $\mathrm{n}$ & & & \\
\hline Fricative & & $\mathrm{s}$ & & & & & $\mathrm{h}$ \\
\hline Tap & & $\mathrm{r}$ & & & & & \\
\hline Approximant & $\mathrm{w}$ & & $\kappa$ & $\mathrm{j}$ & & & \\
\hline Lateral & & $\mathrm{l}$ & & & & &
\end{tabular}




\section{Appendix B}

Stimuli used in real word repetition tasks

\begin{tabular}{|c|c|}
\hline Real word* & Translation \\
\hline 'warmi & 'woman' training trial \\
\hline 'wasi & 'house' training trial \\
\hline 'qhari & 'man' training trial \\
\hline 'chita & 'sheep' \\
\hline 'p'esqo & 'bird' \\
\hline ju'k'ucha & 'mouse' \\
\hline 'waka & 'cow' \\
\hline 'wallpa & 'chicken' \\
\hline 'mama & 'mom' \\
\hline 'papa & 'potato' \\
\hline 't'ika & 'flower' \\
\hline 'llama & 'llama' \\
\hline 'cuca & 'coca (leaves)' \\
\hline u'hut'a & 'sandal' \\
\hline ham'piri & 'healer' \\
\hline i'milla & 'girl' \\
\hline 'llapa & 'lightning' \\
\hline 'api & 'corn/citrus drink' \\
\hline 'ch'ulu & 'hat' \\
\hline 'punku & 'door' \\
\hline 'thapa & 'nest' \\
\hline 'punchu & 'poncho' \\
\hline 'pampa & 'prairie' \\
\hline 'sunkha & 'beard' \\
\hline hatun'mama & 'grandma' \\
\hline 'wawa & 'baby/child' \\
\hline 'runtu & 'egg' \\
\hline 'qolqe & 'money' \\
\hline 'q'apa & 'palm of hand' \\
\hline 'alqo & 'dog' \\
\hline 'q'epi & 'bundle' \\
\hline
\end{tabular}

* For the real words, ' indicates stress, ' indicates ejective 
Appendix C

Real word repetition stimuli to elicit [ap]

\begin{tabular}{|c|c|c|}
\hline Real word* & Translation & Morpheme environment ${ }^{\dagger}$ \\
\hline chi'ta-pi & 'sheep-LOC' & across \\
\hline cu'ca-pi & 'coca (leaves)-LOC' & across \\
\hline hatunma'ma-pi & 'grandma-LOC' & across \\
\hline imi'lla-pi & 'girl-LOC' & across \\
\hline juk'u'cha-pi & 'mouse-LOC' & across \\
\hline lla'ma-pi & 'llama-LoC' & across \\
\hline lla'pa-pi & 'lightning-LOC' & across \\
\hline ma'ma-pi & 'mom-LOC' & across \\
\hline pam'pa-pi & 'prairie-LOC' & across \\
\hline pa'pa-pi & 'potato-LOC' & across \\
\hline q'a'pa-pi & 'palm of hand-LOC' & across \\
\hline sun'kha-pi & 'beard-LOC' & across \\
\hline t'i'ka-pi & 'flower-LOC' & across \\
\hline tha'pa-pi & 'nest-LOC' & across \\
\hline uhu't'a-pi & 'sandal-LOC' & across \\
\hline wa'ka-pi & 'cow-LOC' & across \\
\hline wall'pa-pi & 'chicken-LOC' & across \\
\hline wa'wa-pi & 'baby/child-LOC' & across \\
\hline 'papa & 'potato' & within \\
\hline 'llapa & 'lightning' & within \\
\hline 'api & 'corn/citrus drink' & within \\
\hline 'thapa & 'nest' & within \\
\hline 'q'apa & 'palm of hand' & within \\
\hline
\end{tabular}


Appendix D

Real word repetition stimuli to elicit [am]

\begin{tabular}{c|c|c}
\hline Real word* & Translation & Morpheme environment \\
\hline chi'ta-man & 'sheep-ALL' & across \\
cu'ca-man & 'coca (leaves)-ALL' & across \\
hatunma'ma-man & 'grandma-ALL' & across \\
imi'lla-man & 'girl-ALL' & across \\
juk'u'cha-man & 'mouse-ALL' & across \\
lla'ma-man & 'llama-ALL' & across \\
lla'pa-man & 'lightning-ALL' & across \\
ma'ma-man & 'mom-ALL' & across \\
pam'pa-man & 'prairie-ALL', & across \\
pa'pa-man & 'potato-ALL' & across \\
q'a'pa-man & 'palm of hand-ALL' & across \\
sun'kha-man & 'beard-ALL', & across \\
t'i'ka-man & 'flower-ALL' & across \\
tha'pa-man & 'nest-ALL' & across \\
wa'ka-man & 'cow-ALL' & across \\
wall'pa-man & 'chicken-ALL' & across \\
wa'wa-man & 'baby/child-ALL' & across \\
\hline 'mama & 'mom' & within \\
'llama & 'llama' & within \\
ham'piri & 'healer' & within \\
hampi'ri-pi & 'healer-LOC' & within \\
'pampa & 'prairie' & within \\
hatun'mama & 'grandma' & within \\
\hline
\end{tabular}

* ' indicates stress, ' indicates ejective 


\section{Appendix E}

Model predicting coarticulation in children and adults

\begin{tabular}{|c|c|c|c|c|c|}
\hline term & estimate & S.E. & z.statistic & p.value & $95 \% \mathrm{CI}$ \\
\hline Intercept & 204.61 & 4.67 & 43.86 & 0.00 & $2.14,1.95$ \\
\hline Syllable count:2 & 9.48 & 2.05 & 4.62 & 0.00 & $0.13,0.05$ \\
\hline Syllable count:3 & -3.31 & 0.95 & -3.47 & 0.00 & $-0.01,-0.05$ \\
\hline Syllable count: 4 & -1.12 & 1.36 & -0.82 & 0.41 & $0.02,-0.04$ \\
\hline Sequence duration & 0.29 & 0.06 & 4.99 & 0.00 & 0,0 \\
\hline VC sequence:ap & 61.68 & 5.31 & 11.62 & 0.00 & $0.72,0.51$ \\
\hline Age:child & 6.07 & 4.75 & 1.28 & 0.20 & $0.15,-0.03$ \\
\hline Environment:across morpheme & 5.73 & 6.35 & 0.90 & 0.37 & $0.18,-0.07$ \\
\hline Sequence duration*VC sequence:ap & -0.15 & 0.07 & -2.18 & 0.03 & 0,0 \\
\hline Sequence duration*Age:child & -0.21 & 0.06 & -3.39 & 0.00 & 0,0 \\
\hline VC sequence:ap*Age:child & 6.83 & 6.10 & 1.12 & 0.26 & $0.19,-0.05$ \\
\hline Sequence duration*Environment:across morpheme & -0.11 & 0.08 & -1.31 & 0.19 & 0,0 \\
\hline VC sequence:ap*Environment:across morpheme & 9.12 & 6.95 & 1.31 & 0.19 & $0.23,-0.05$ \\
\hline Age:child:Environmentacross morpheme & 0.42 & 6.30 & 0.07 & 0.95 & $0.13,-0.12$ \\
\hline Sequence duration*VC sequence:ap*Age:child & 0.13 & 0.08 & 1.68 & 0.09 & 0,0 \\
\hline Sequence duration*VC sequence:ap*Environment:across morpheme & 0.16 & 0.09 & 1.69 & 0.09 & 0,0 \\
\hline Sequence duration*Age:child*Environment:across morpheme & 0.13 & 0.09 & 1.56 & 0.12 & 0,0 \\
\hline VC sequence:ap*Age:child*Environment:across morpheme & -8.35 & 7.69 & -1.09 & 0.28 & $0.07,-0.23$ \\
\hline Sequence duration*VC sequence:ap*Age:child*Environment:across morpheme & -0.28 & 0.10 & -2.75 & 0.01 & 0,0 \\
\hline
\end{tabular}




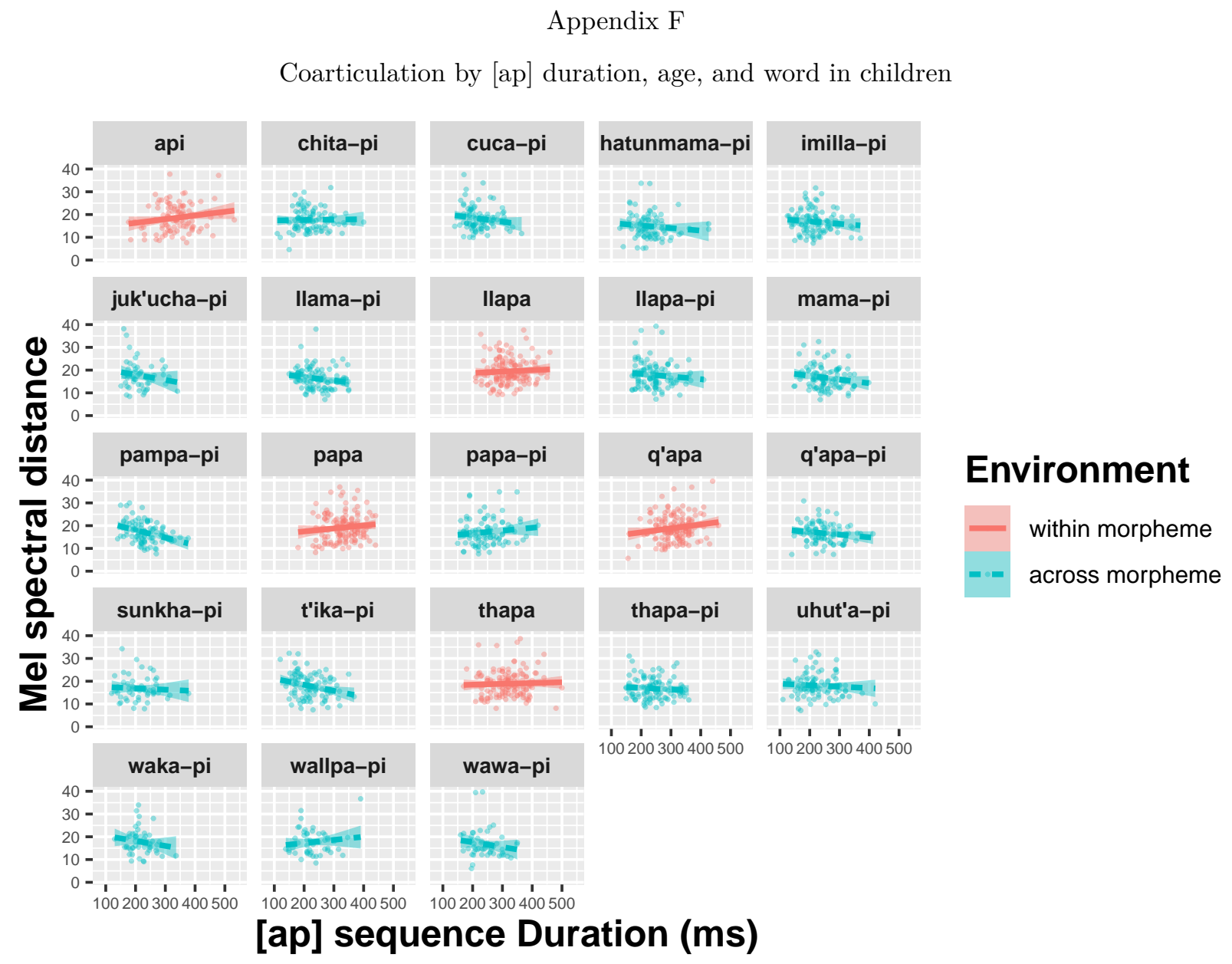


Appendix G

Mean VC sequence duration by number of syllables in word for children

\begin{tabular}{lrrrrr}
\hline & \multicolumn{2}{c}{$[\mathrm{am}]$} & & \multicolumn{2}{c}{$[\mathrm{ap}]$} \\
\cline { 2 - 3 } \cline { 5 - 6 } Syllables & Duration $(\mathrm{ms})$ & $\mathrm{SD}$ & & Duration $(\mathrm{ms})$ & $\mathrm{SD}$ \\
\hline 2 & 272.9 & 52 & & 325.3 & 57 \\
3 & 211.6 & 51 & & 235.2 & 51 \\
4 & 207.6 & 46 & & 220.7 & 51 \\
5 & 204.1 & 35 & & 230.4 & 51 \\
\hline
\end{tabular}




\section{Appendix $\mathrm{H}$}

Mean VC sequence duration by number of syllables in word for adults

\begin{tabular}{lrrrrr}
\hline & \multicolumn{2}{c}{$[\mathrm{am}]$} & & \multicolumn{2}{c}{$[\mathrm{ap}]$} \\
\cline { 2 - 3 } \cline { 5 - 6 } Syllables & Duration $(\mathrm{ms})$ & $\mathrm{SD}$ & & Duration $(\mathrm{ms})$ & $\mathrm{SD}$ \\
\hline 2 & 177.6 & 39 & & 192.4 & 57 \\
3 & 176.5 & 35 & & 210.0 & 50 \\
4 & 168.0 & 36 & & 195.3 & 43 \\
5 & 178.5 & 51 & & 207.3 & 40 \\
\hline
\end{tabular}


Appendix I

Coarticulation by sequence duration, word, and morphological environment in children

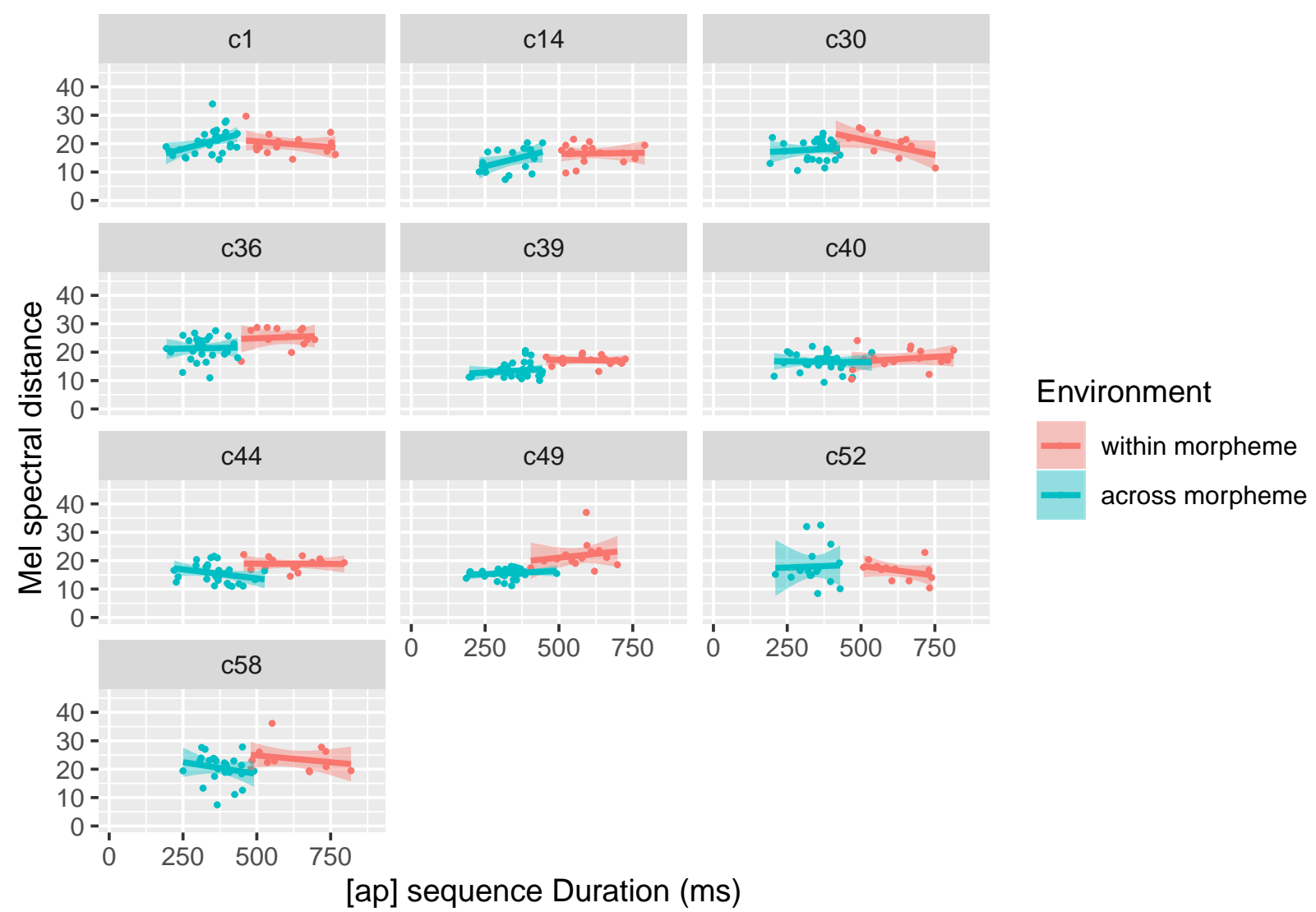

Figure I1. Coarticulation by [ap] duration, word, and morphological environment in five-year-old children 


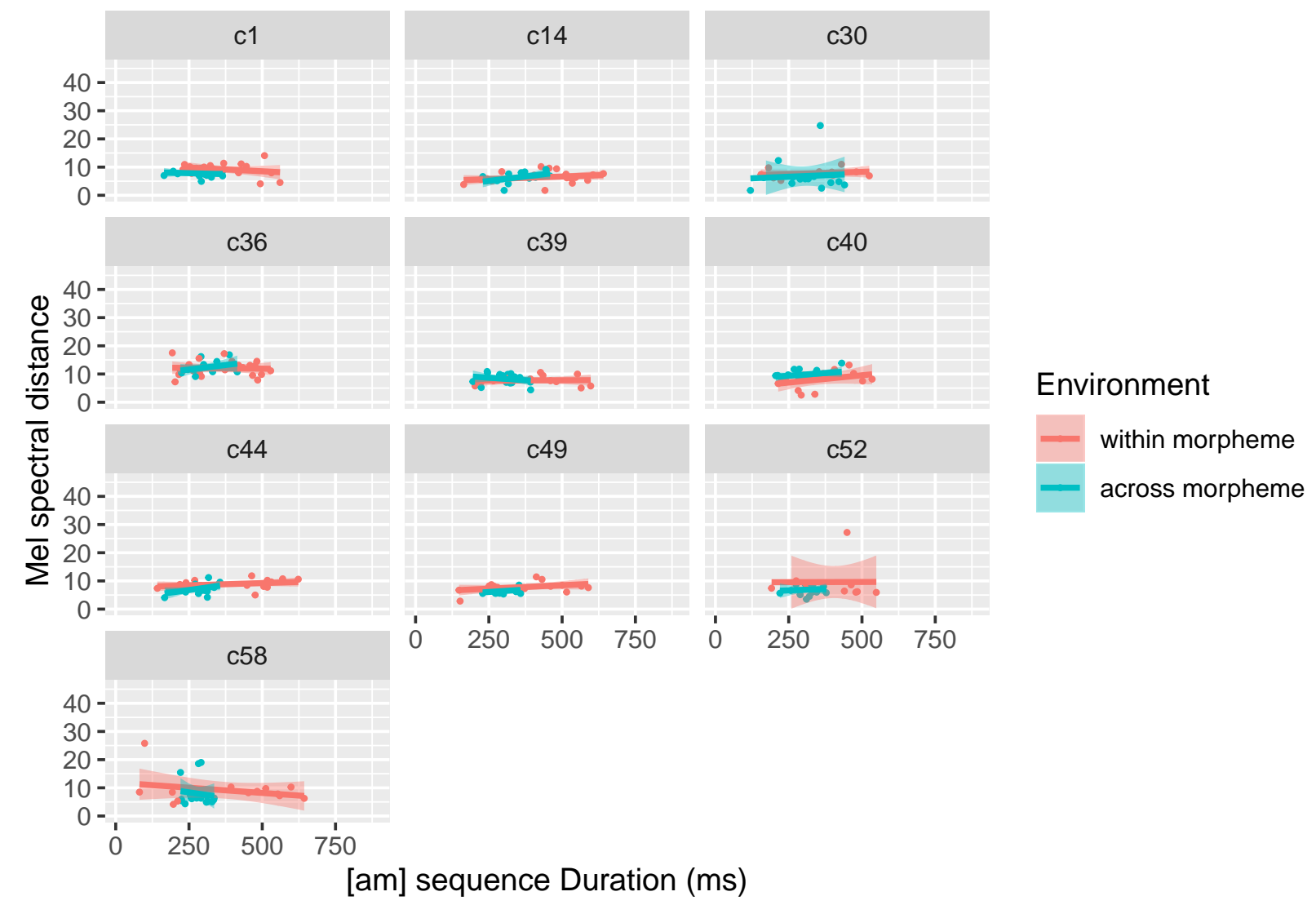

Figure I2. Coarticulation by [am] duration, word, and morphological environment in five-year-old children 


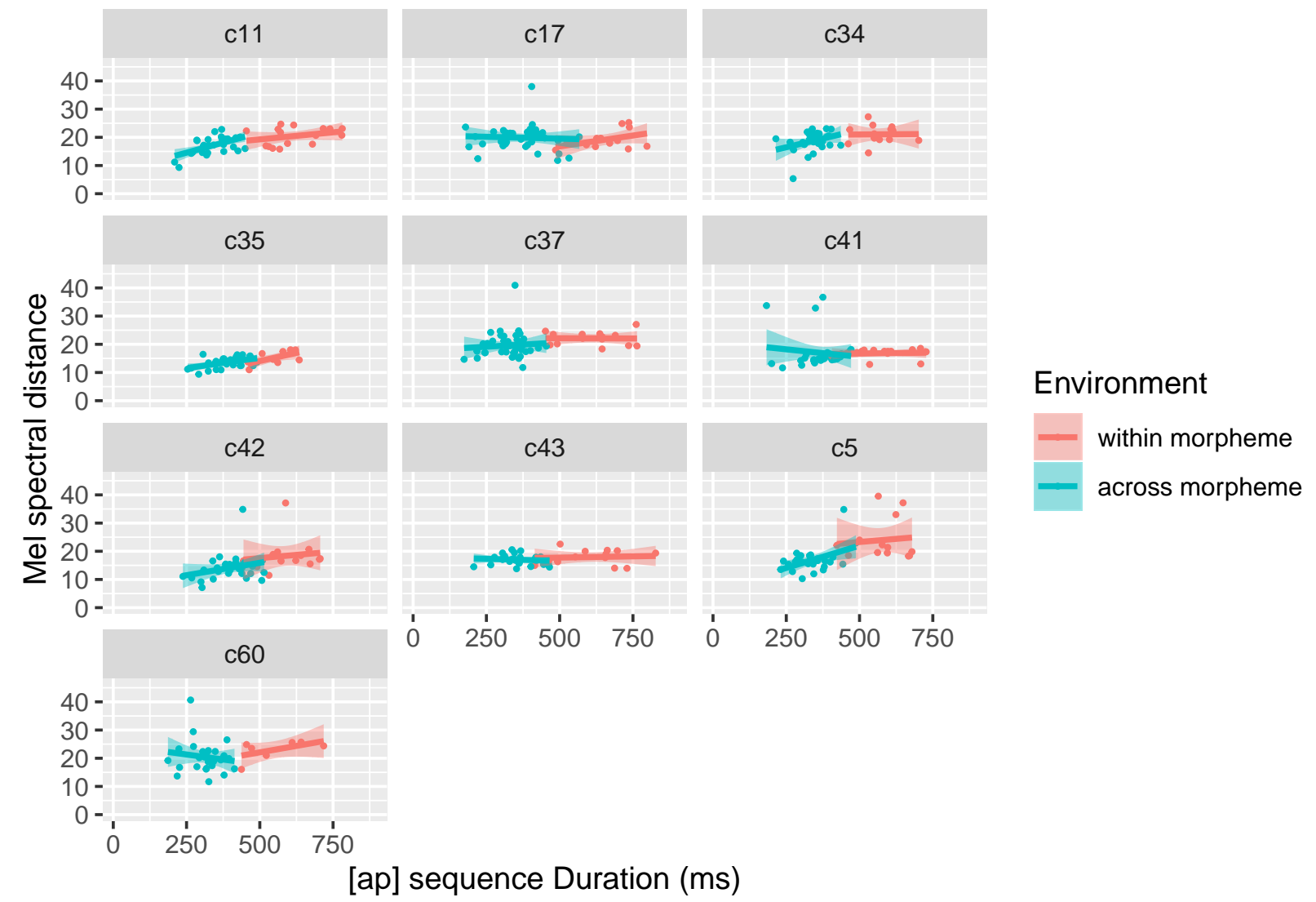

Figure I3. Coarticulation by [ap] duration, word, and morphological environment in six-year-old children 


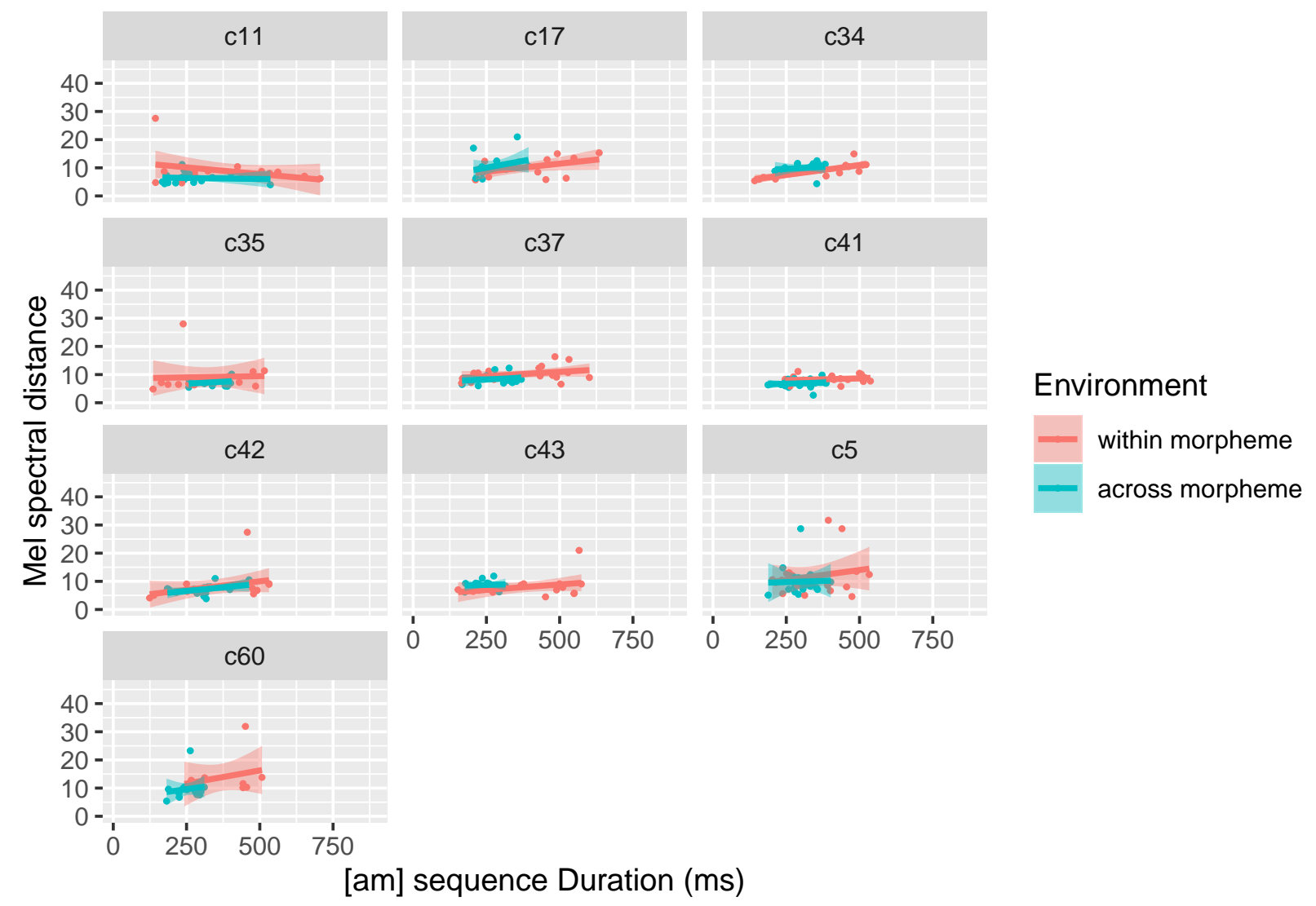

Figure I4. Coarticulation by [am] duration, word, and morphological environment in six-year-old children 


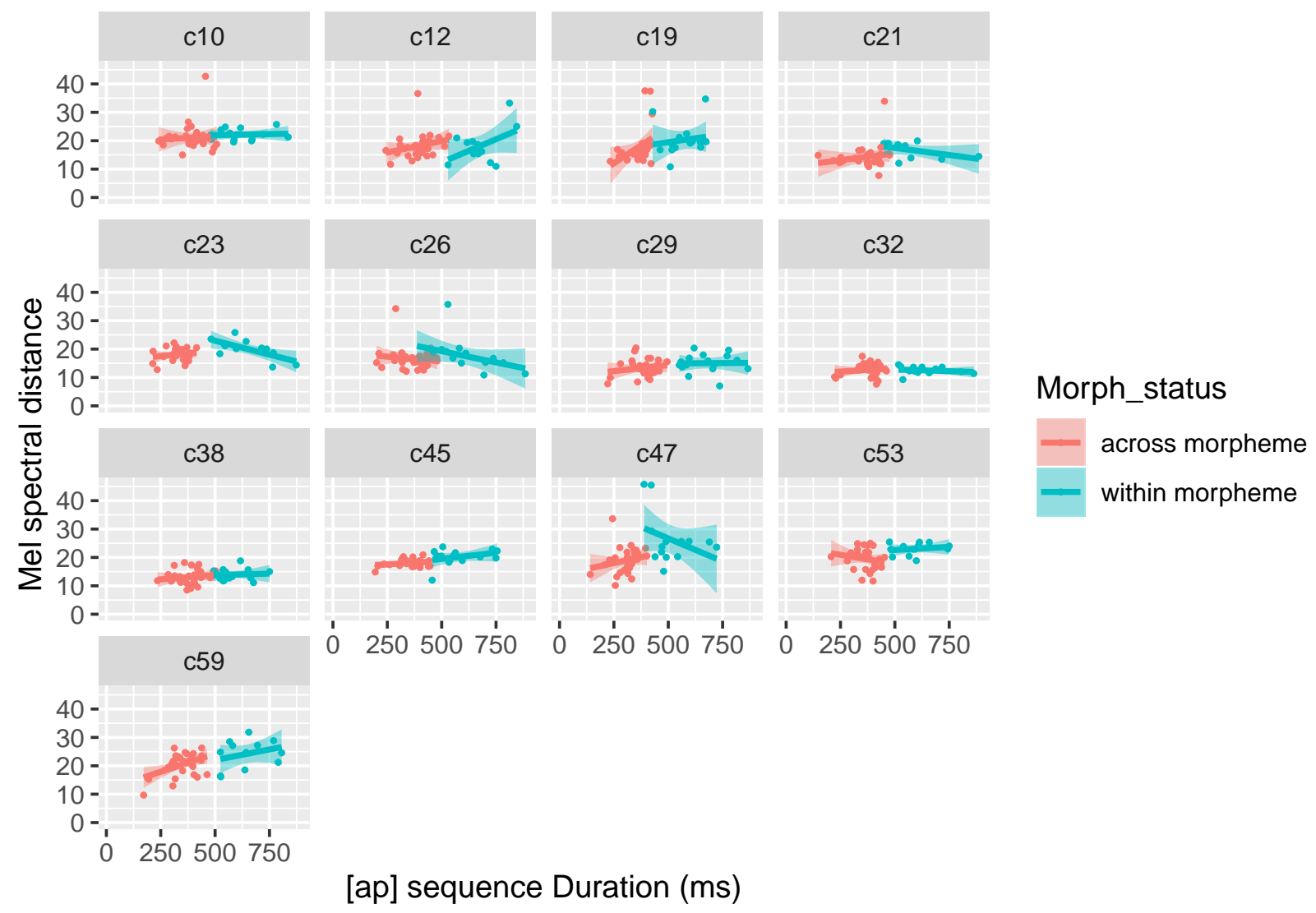

Figure I5. Coarticulation by [ap] duration, word, and morphological environment in seven-year-old children 


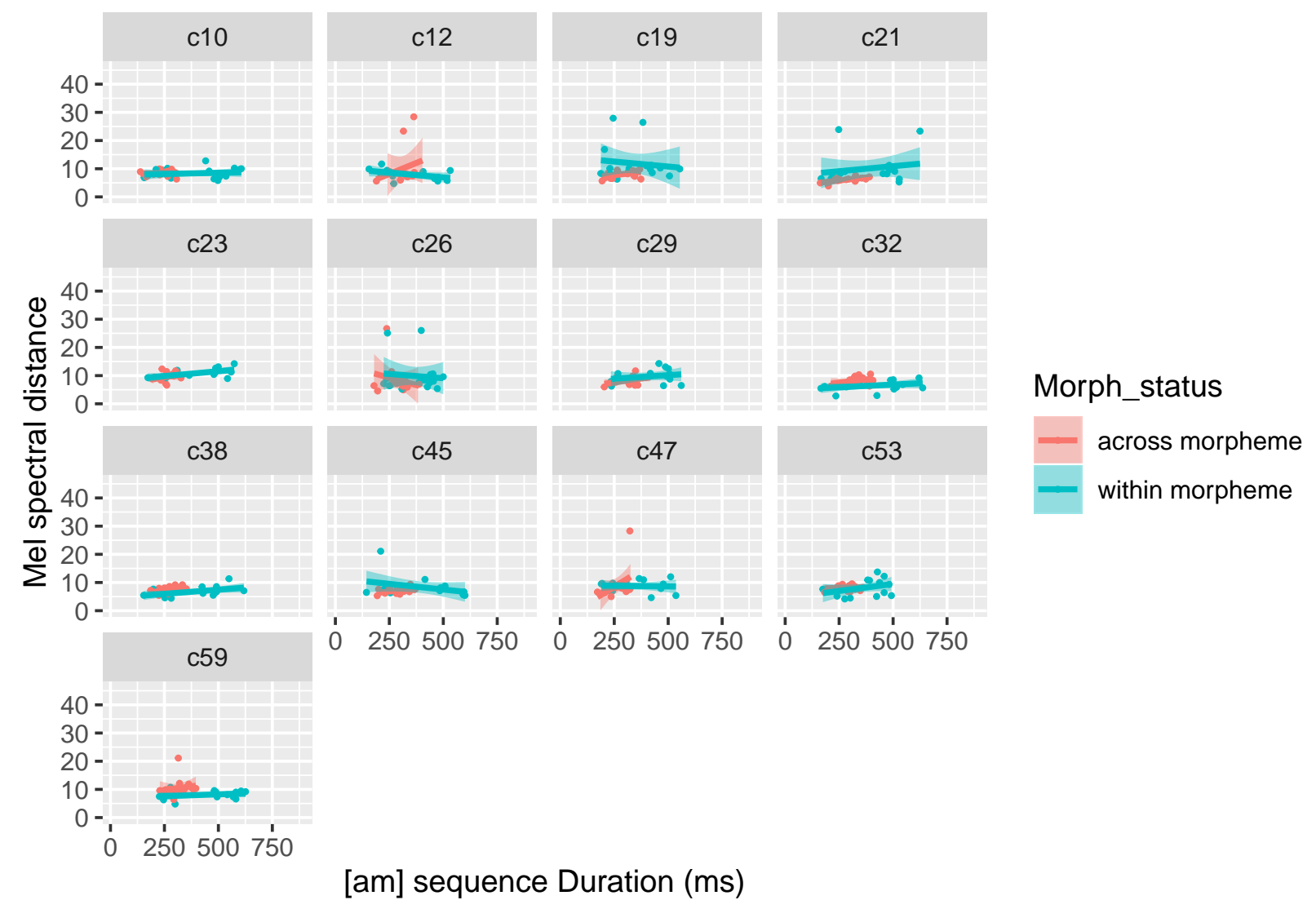

Figure I6. Coarticulation by [am] duration, word, and morphological environment in seven-year-old children 


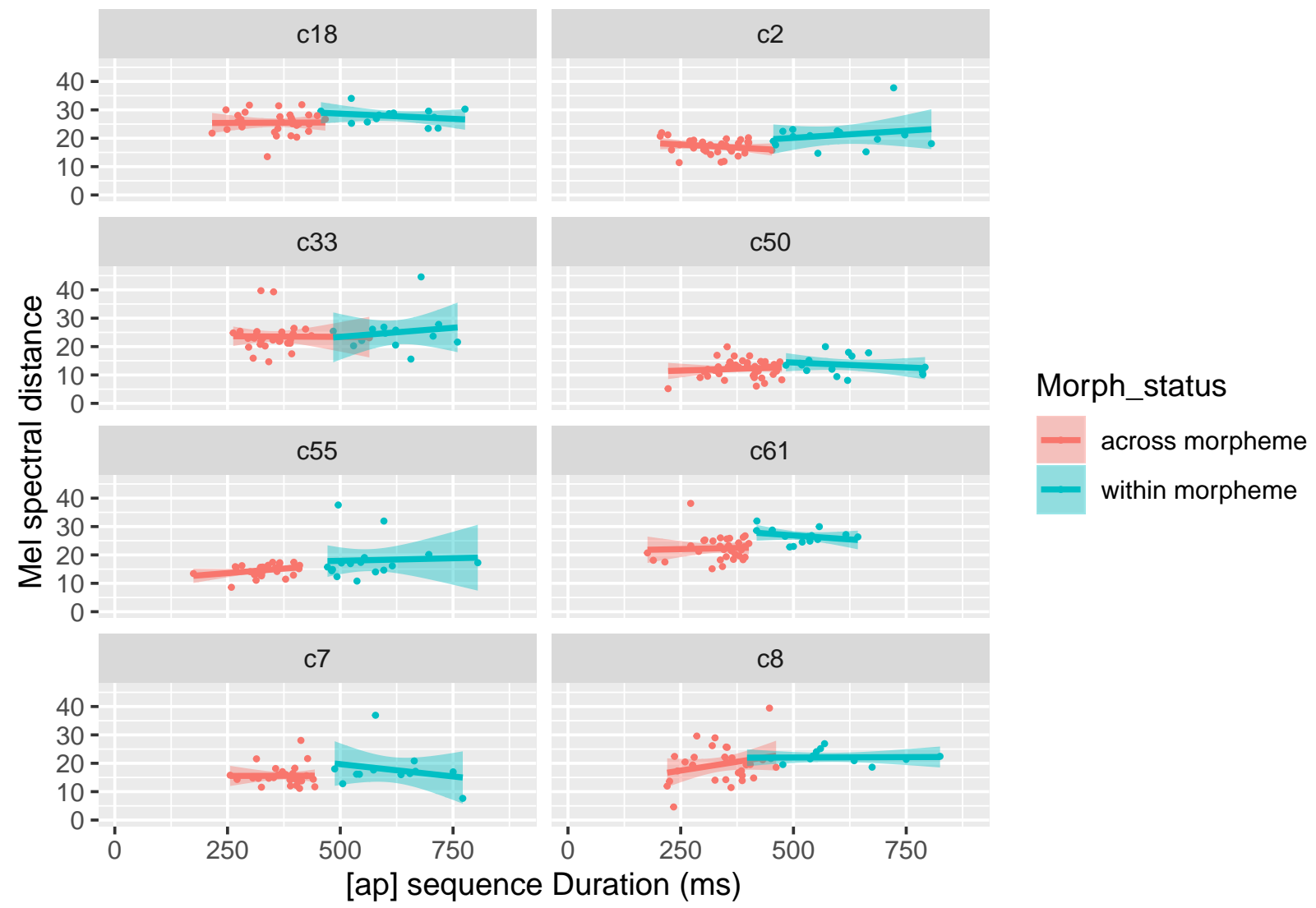

Figure I\%. Coarticulation by [ap] duration, word, and morphological environment in eight-year-old children 


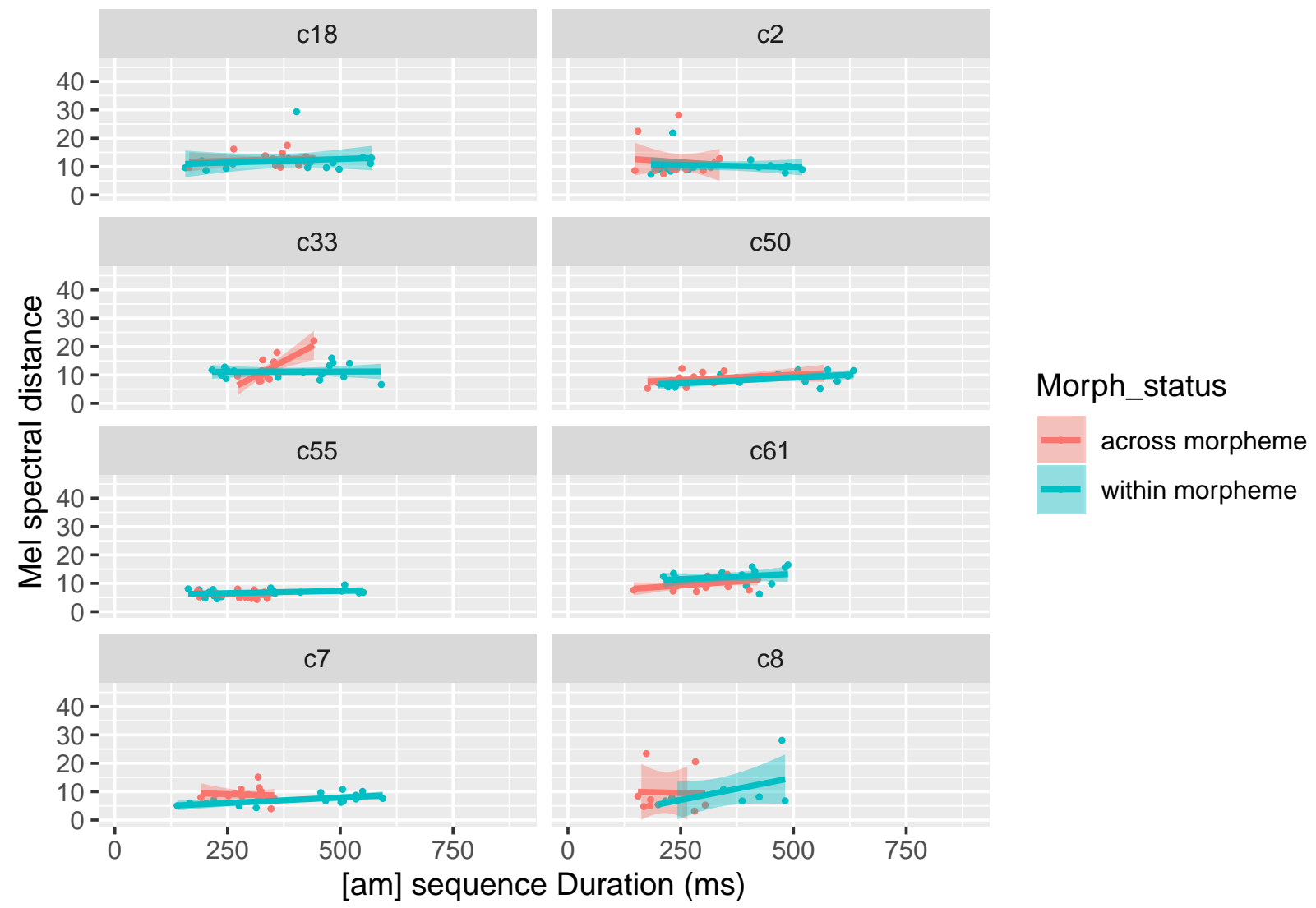

Figure 18. Coarticulation by [am] duration, word, and morphological environment in eight-year-old children 


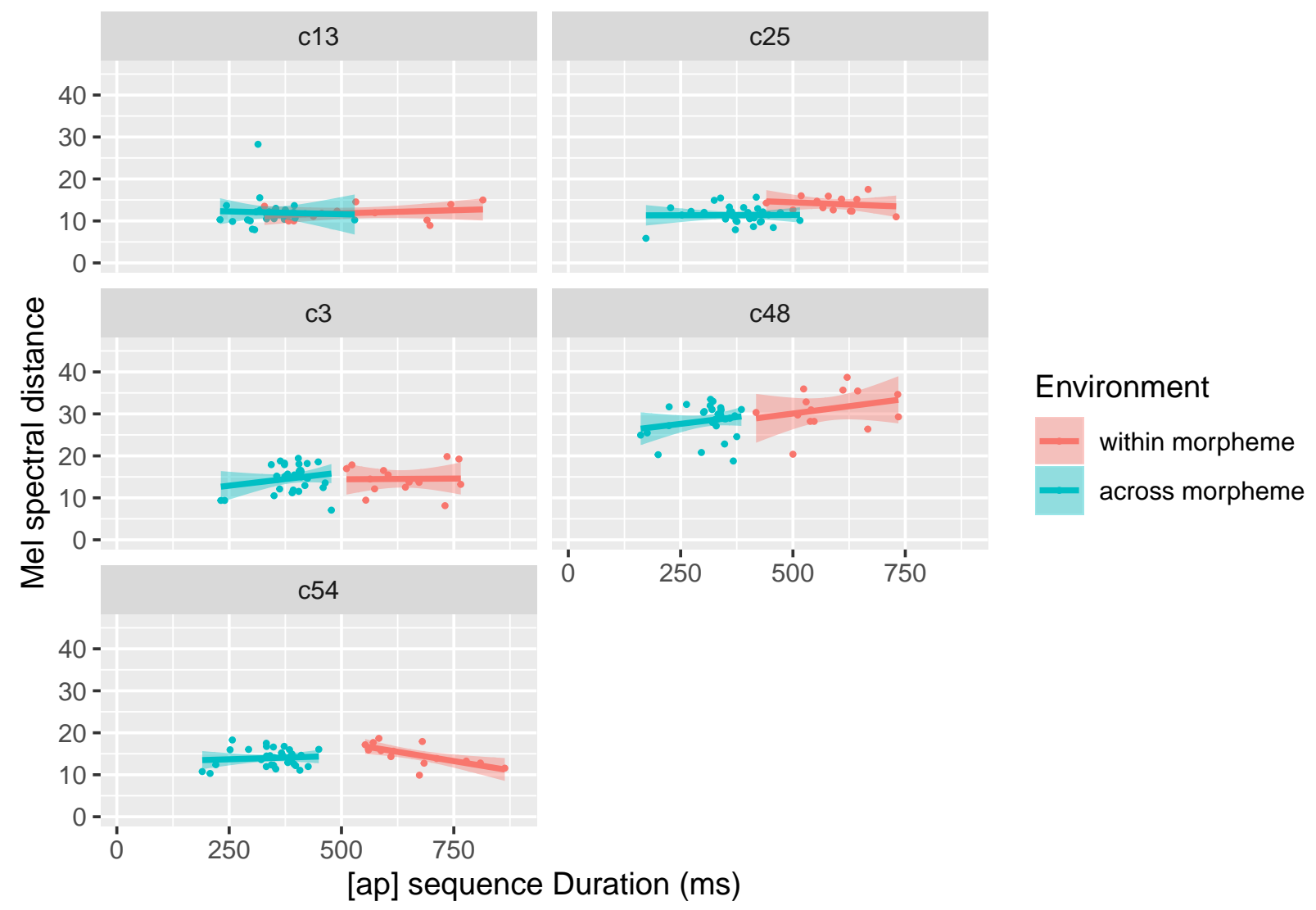

Figure I9. Coarticulation by [ap] duration, word, and morphological environment in nine-year-old children 


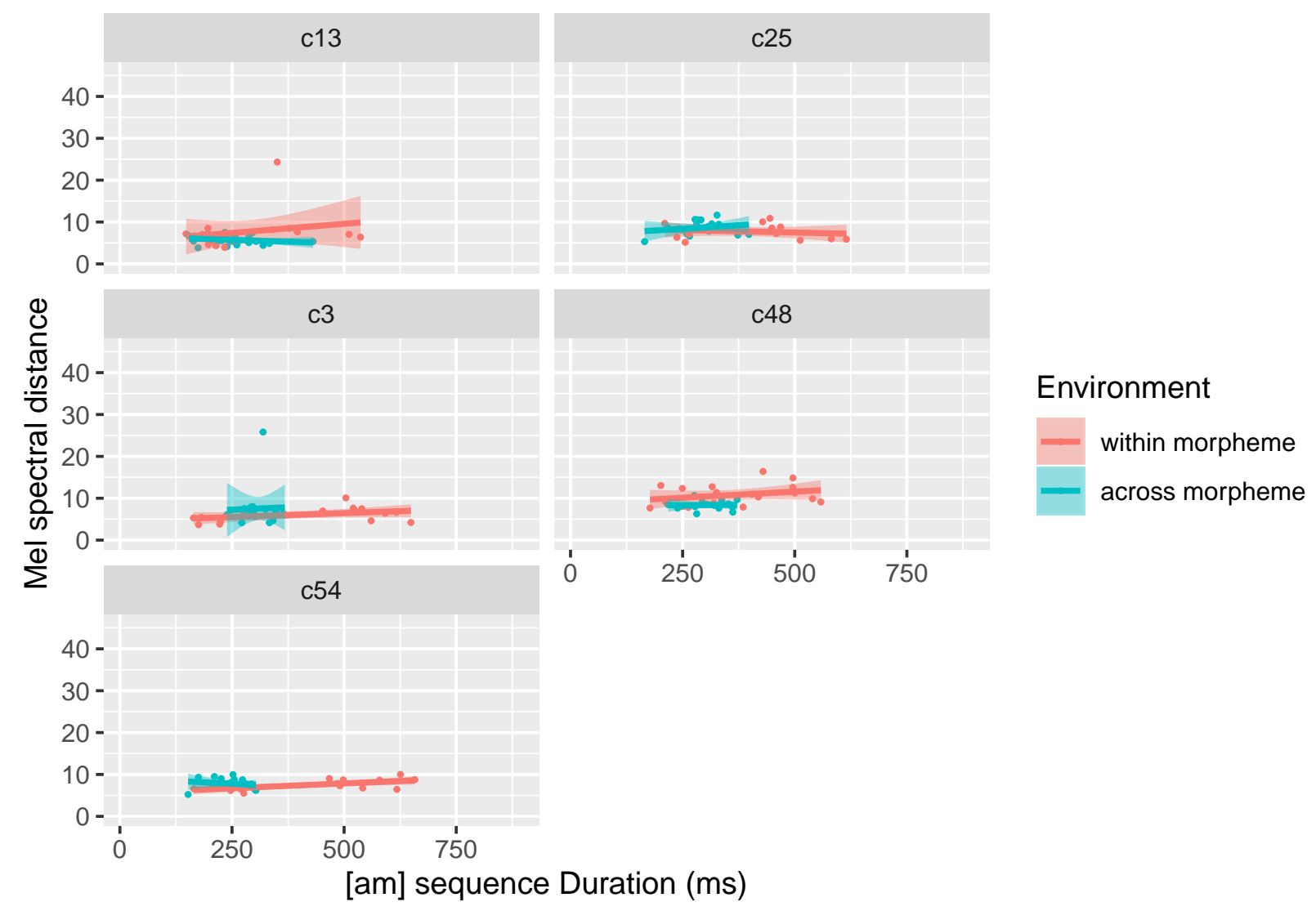

Figure I10. Coarticulation by [am] duration, word, and morphological environment in nine-year-old children 


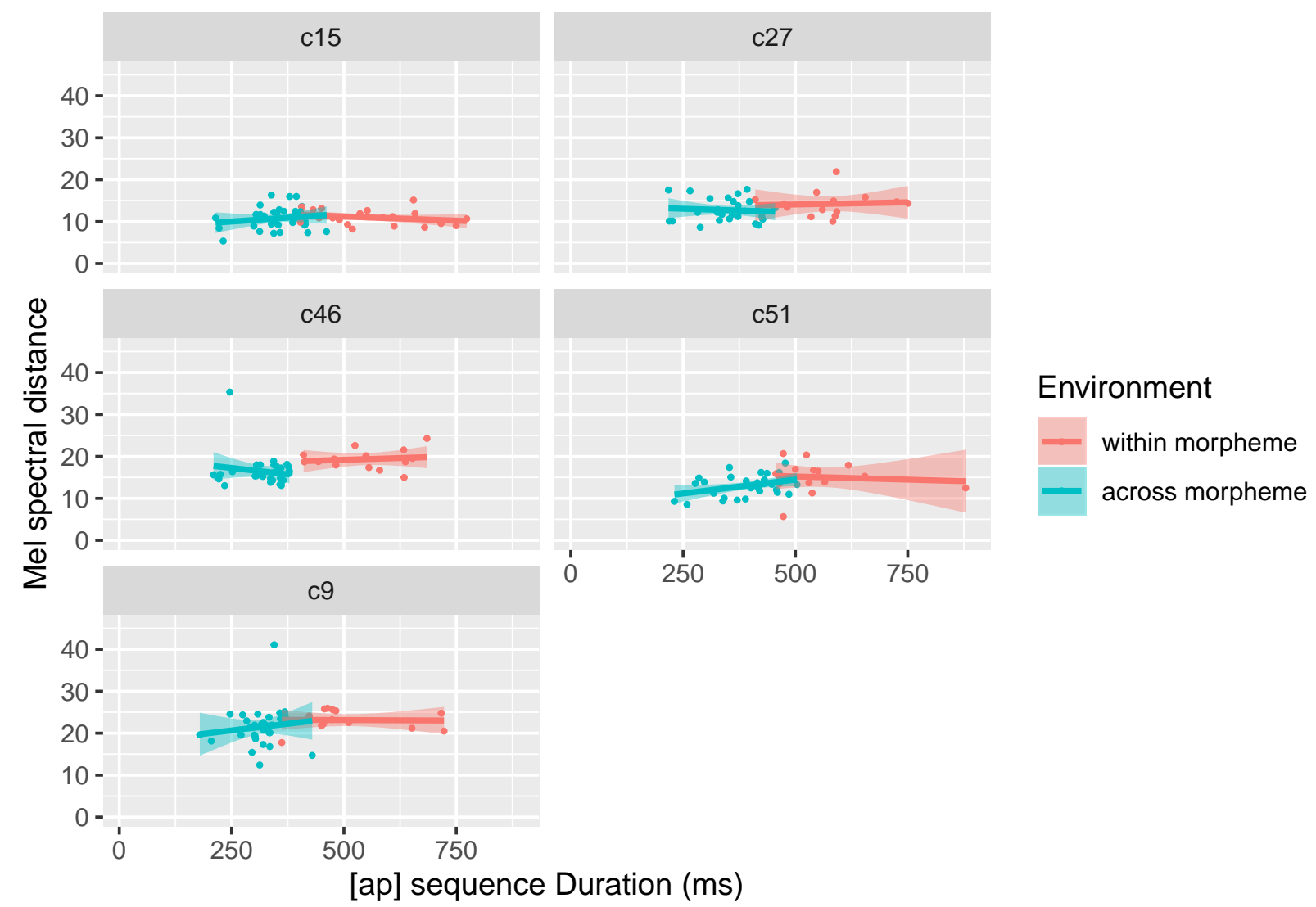

Figure I11. Coarticulation by [ap] duration, word, and morphological environment in ten-year-old children 


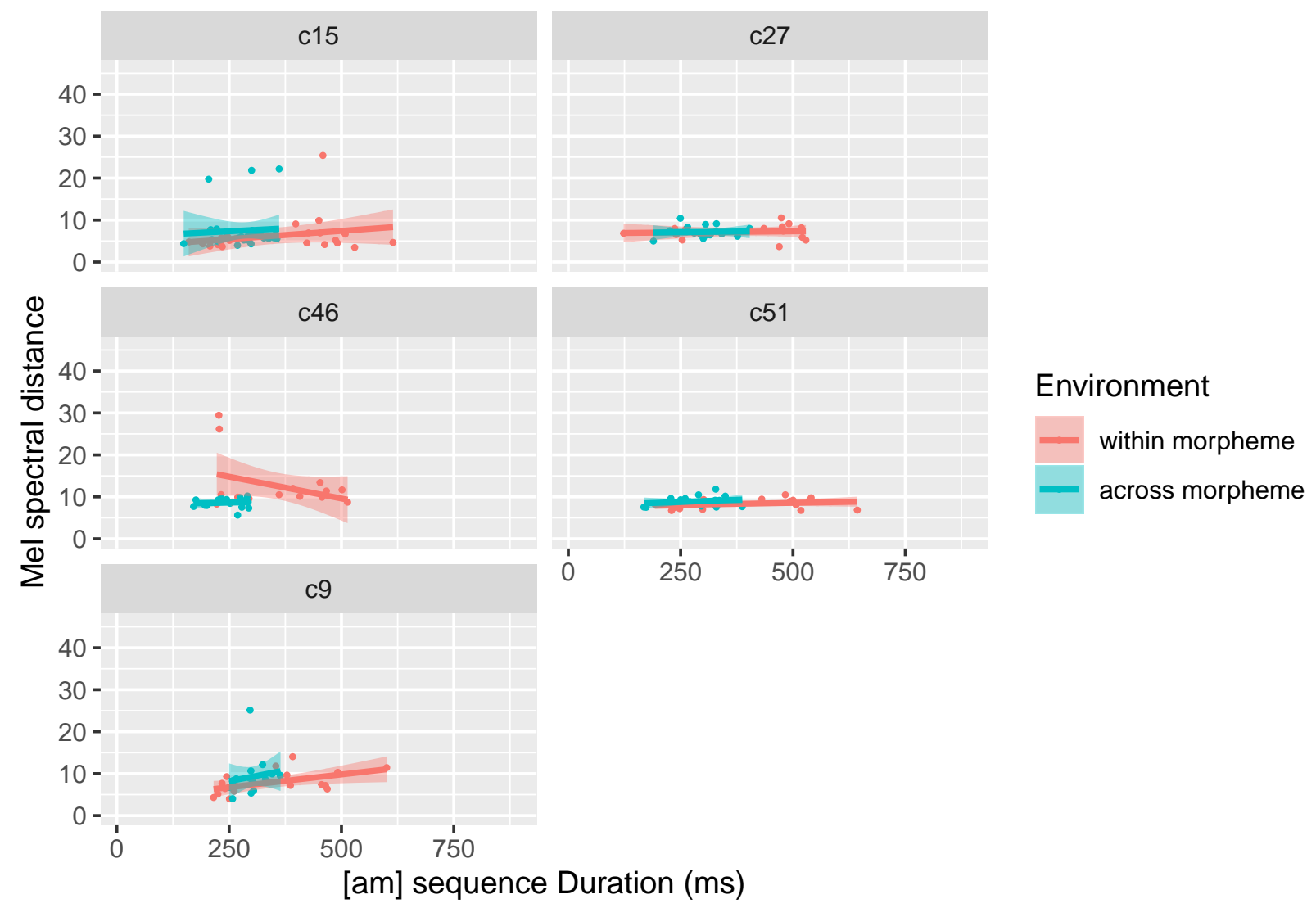

Figure 112. Coarticulation by [am] duration, word, and morphological environment in ten-year-old children 